\title{
Paddy Water Management for Precision Farming of Rice
}

\author{
M.S.M. Amin, M.K. Rowshon and W. Aimrun \\ Smart Farming Technology Centre of Excellence \\ Department of Biological and Agricultural Engineering, Faculty of Engineering, \\ Universiti Putra Malaysia (UPM), 43400 UPM Serdang, Selangor DE, \\ Malaysia
}

\section{Introduction}

Irrigation is the largest water user in the world, using up to $85 \%$ of the available water in the developing countries [1]. A lot of irrigation water is used in the production of rice as the staple food of more than half the world population. However, despite the constraints of water scarcity, rice production must be raised to feed the growing population. Producing more rice with less water is therefore a formidable challenge for food, economic, social and water security.

Asia is relatively well endowed with water resources, but water resources per inhabitant are only slightly above half of the world's average. Countries like India and China are approaching the limit of water scarcity. About $84 \%$ of water withdrawal is for agriculture, with major emphasis on flooded rice irrigation. There has been a rapid increase in irrigation development. Most countries have achieved self-sufficiency in rice. Schemes are designed primarily to secure rice cultivation in the main cropping season. Some countries design new irrigation schemes for year-round irrigation. Rice represents about $45 \%$ of irrigated areas and $59 \%$ of the rice land is irrigated. Average cropping intensity is $127 \%$. The 28 million hectares under intense irrigation producing two to three crops per year suffer from declining productivity.

Growth in irrigated areas has declined in recent years. Groundwater draw-down has reached alarming levels in many areas. Declining prices of rice, higher marginal development costs, environmental concerns, and poor performance of existing schemes are among the main factors of the decline in irrigation growth and investment both by governments and farmers.

Increased competition for water between sectors already affects agriculture. Poor operation and maintenance of large public schemes has led to irrigation management transfer or increased participation of users through water users' associations. Socio-economic changes and water scarcity call for a transformation of irrigation by the adoption of measures to modify water demands and maximize efficiency in water use, to improve its economic, technical, and environmental performance, together with diversification of produce and cropping patterns, changes in management systems and structures, financial and fiscal 
sustainability. But rehabilitation programs are assuming increasing importance. Progress in modernization is slow when compared with other regions.

Scenarios for growth in water demand suggest that because of the projected increases in food demand, irrigated food production will need to increase significantly. Demand from other sectors will also increase because of economic development and increase in population. Nearly all countries in the region will need to invest considerable efforts and resources in a mixture of improved demand management of the water sector and interventions on the supply side to achieve the very considerable improvements in water use which are required. But approximately 1 billion people would live in regions of absolute water scarcity.

Therefore there is a need to improve water productivity as well as water use efficiency. Land preparation, land soaking for maintaining water level in the paddy fields and soil saturation require more water than plant transpiration. System and farm irrigation efficiency is quite low (in the range of 30 to $40 \%$ ). A river basin perspective should be adopted, defining the boundaries of intervention (farm, system, river basin), paying attention to managing the return flows and to water quality. However, practices which minimize irrigation inflow are of a direct interest to farmers who receive less water and more costly water. In the long run, sustainability of irrigated agriculture will ensure sustainable environment for all human beings.

Environmental sustainability is very synonymous with precision farming or site-specific management. Precision farming requires quick soil spatial variability description for decision-making on the right input at the right place, at the right time and in the right amount or site-specific zone management. VerisEC sensor is used widely for spatial variability description and it relates to soil properties such as salt concentration, texture and cation exchange capacity (CEC), an indication of the soils potential to hold plant nutrients. It is a sensor to measure the ability of soil in conducting electrical current using rotating discs as electrodes, which penetrate $6 \mathrm{~cm}$ into the soil, while pulled through the field by a tractor and locations determined by GPS. For upland crops, farmers use VerisEC to measure $\mathrm{EC}_{\mathrm{a}}$ at shallow and deep depths for Nitrogen management and hardpan depth determination.

Land management zone delineation using soil electrical conductivity (MAZDEC) shortens the time taken to determine paddy soil variability, can be utilized for zoning of paddy fields, and helps rice farmers in site-specific application of their inputs. MAZDEC can complement a detailed soil series map and can be used as an estimator for soil physical and chemical properties. MAZDEC allows directed soil sampling to replace grid sampling, allows topping-up of the required nutrients at the needed rate at the right place and time. Each farmer will be able to quickly determine the soil management zones for variable application rates of seed, fertilizers, and water. Making this information available on-line to the farmers will be a major step in making available the benefits of new technologies.

\section{Irrigation water management}

\subsection{Research on rice irrigation water management}

In Malaysia, about $70 \%$ of the available water resources are consumed for rice production. Due to rapidly growing population and water competition among different sectors it is 
imperative that the available irrigation supplies be used efficiently. A small improvement of water use in rice production would result in significant water savings for other sectors. Traditionally rice is grown under continuous submergence or intermittent or variable ponding conditions depending on the farmer's choice and also on the available water resources. Continuous submergence with 5 to $7 \mathrm{~cm}$ of water is probably the best for irrigated rice considering all factors and extremely deep water resulted in poor growth and yield [2]. To evaluate the effect of ponding water depth on rice yield, the $9 \mathrm{~cm}$ of ponding water depth in Wagner's pots (a growth chamber $25 \mathrm{~cm}$ diameter and $30 \mathrm{~cm}$ height, filled with soil up to $15 \mathrm{~cm}$ depth) gave the optimum rice growth and yield [3]. Therefore, the importance of controlled water supply and monitoring is indispensable for the sustainability of rice production, which varies enormously from region to region.

Performance assessment has been prioritized as the most critical element to improve irrigation management [4]. Various analytical frameworks, criteria and indicators are available to understand the factors that influence the performance of irrigation system and to quantify water delivery performance. Some of them are suitable to identifying reasons for poor performance and prescribing management and physical interventions to improve the performance. All performance indicators have their own strengths and weaknesses. Many performance indicators fail to quantify reliability, adequacy and equity aspects of water distribution although many performance indicators are useful for quantifying the water delivery for irrigation seasons. Many performance indicators are useful for post-season evaluation but they are not useful as management tools which can be used to keep track of irrigation delivery performance during a crop growing season. If a particular indicator is useful both as a management tool and as an indicator of the overall irrigation delivery performance for any given irrigation interval or season, its credibility is undoubtedly superior to the other performance measures.

Detailed reviews for the advantages and disadvantages for various performance assessment methodologies [5] emphasized the simplest indicator of evaluating water delivery performance and how tightly adequate water can be delivered to the fields. The available water supply and the water demand are the most crucial factors in irrigation planning, design and operation of an irrigation system. A performance indicator [6], which is called Relative Water Supply (RWS), is simply the ratio of irrigation supply and demand. Detailed application and weakness have been described for monitoring and assessing of irrigation water delivery performance for rice irrigation scheme using the RWS concept [7 \& 8]; and further illustration on the use of the RWS concept based on field research [9 \& 10]. The RWS concept has been widely used to assess the performance of irrigation systems. Indeed for paddy irrigation, quantifying of the upper bound value of RWS for oversupply condition is a difficult task due to the many variables that influence the performance of irrigated agriculture. Therefore, it is essential to have an appropriate tool with feasible options to improve the performance of the irrigation supplies for rice production.

The water demand for rice irrigation is completely different from upland crops. To replenish the field water level up to the Maximum Ponding Water Depth (WSmax $)_{j}$ for a particular period, the amount of water for the difference between the Maximum Ponding Water Depth $\left(W_{S m a x}\right)$ and the Present Ponding Water Depth $\left(\mathrm{WS}_{\mathrm{j}}\right)$ is gradually delivered to the paddy fields. The RWS concept incorrectly characterizes irrigation delivery performance for not considering this amount of water $\left(W_{S m a x}-W_{j}\right)$ in the denominator. Due to this, RWS 
gives a wrong scenario to monitor irrigation water delivery performance [11]. To overcome this conflict, new indicators known as Rice Relative Water Supply (RRWS), Cumulative Rice Relative Water Supply (CRRWS) and Ponding Water Index (PWI) are introduced to evaluate the irrigation delivery performance especially for the paddy irrigation system.

To improve irrigation management with variable irrigation supplies, GIS is an essential element for modern information techniques and acts as the interface with the user. To promote more efficient ways of managing water in irrigated areas, modern GIS technique can be employed to collect, store, and process enhanced information on water use for crops, and to disseminate reliable and validated procedures. The modern GIS technique coupled with model can quickly guide the management in decision-making since the temporal and spatial dimensions could be studied at once. The GIS approach is particularly appropriate as it is the most efficient tool for spatial data management and utilization that allows understanding of the spatial variance [12]. GIS has been applied effectively for bringing spatial variability of soil, crop, water supply and environment in dealing with the complex problems for irrigation and water management [13]. GIS is one of the most simple and straightforward ways of providing a management tool for planning of water allocation policy in irrigation system. GIS together with its powerful spatial data management and analysis capabilities is therefore used to extend the scope of the estimation of irrigation delivery performance and its proper evaluation techniques for paddy irrigation system.

\subsection{Study area}

The Tanjung Karang Rice Irrigation Scheme is located at about $3025^{\prime}$ to $3^{0} 45^{\prime} \mathrm{N}$ latitude and $100^{\circ} 58^{\prime}$ to $101^{0} 15^{\prime}$ E longitude in the state of Selangor Malaysia (Fig. 1). The total command area of the scheme is about 18,848 ha. Rice is grown two times in a year mainly from August to January (main- or wet season) and February to July (off- or dry season). The ponding water depth of up to $10 \mathrm{~cm}$ is maintained depending on the crop growth stage, farmer's attitude and available water resources. A unique feature of this irrigation scheme is that it is a run of the river type with no reservoir or dam to store water. The Bernam River is the only source for the irrigation supplies which is diverted at the Bernam River Headwork (BRH) into the feeder canal. Then water is conveyed into Tengi River and thence to the intake point of the main canal at Tengi River Headwork (TRH). The distance from BRH to TRH is about $36 \mathrm{~km}$.

Irrigation water is delivered directly from the main canal to tertiary canals, which are spaced $400 \mathrm{~m}$ apart along the main canal. A standard irrigation block has a net command area of about 150-200 ha. Irrigation blocks receive water in their paddy plots direct from two tertiary canals. A pump house constructed in 1962 on the lower reaches of the Bernam River at Bagan Terap provides water supply for the northern portion of approximately $1000 \mathrm{ha}$. The command areas under pumping condition are not considered in this study. In order to get better utilization of available water resources, the scheme is divided into three irrigation service areas (ISA) where water delivery is staggered by one month starting from August in main season and February in off season. In this way, pre-saturation of the whole project area is completed within three months. The detailed features of the irrigation distribution networks and irrigation compartments under each irrigation service areas namely ISA I (Sawah Sempadan and Sungai Burong), ISA II (Sekinchan, Sungai Leman, Pasir Panjang and Sungai Nipah) and ISA III (Panchang Bedena and Bagan Terap) for the scheme are illustrated in Fig. 1. 
The design discharge at the BRH at the elevation of full supply level (FSL) of $9.6 \mathrm{~m}$ is 30.6 $\mathrm{m}^{3} / \mathrm{s}$. The average annual rainfall is about $1800 \mathrm{~mm}$ [14]. The highest annual evaporation in the area was found to be $1600 \mathrm{~mm}$ during 1990 to 2003. The highest amount of rainfall normally occurs in March-April and October-November for the off season and main season, respectively. The excess water throughout the drainage network is drained out to the sea. This condition is often found for excess rainfall in the main season.

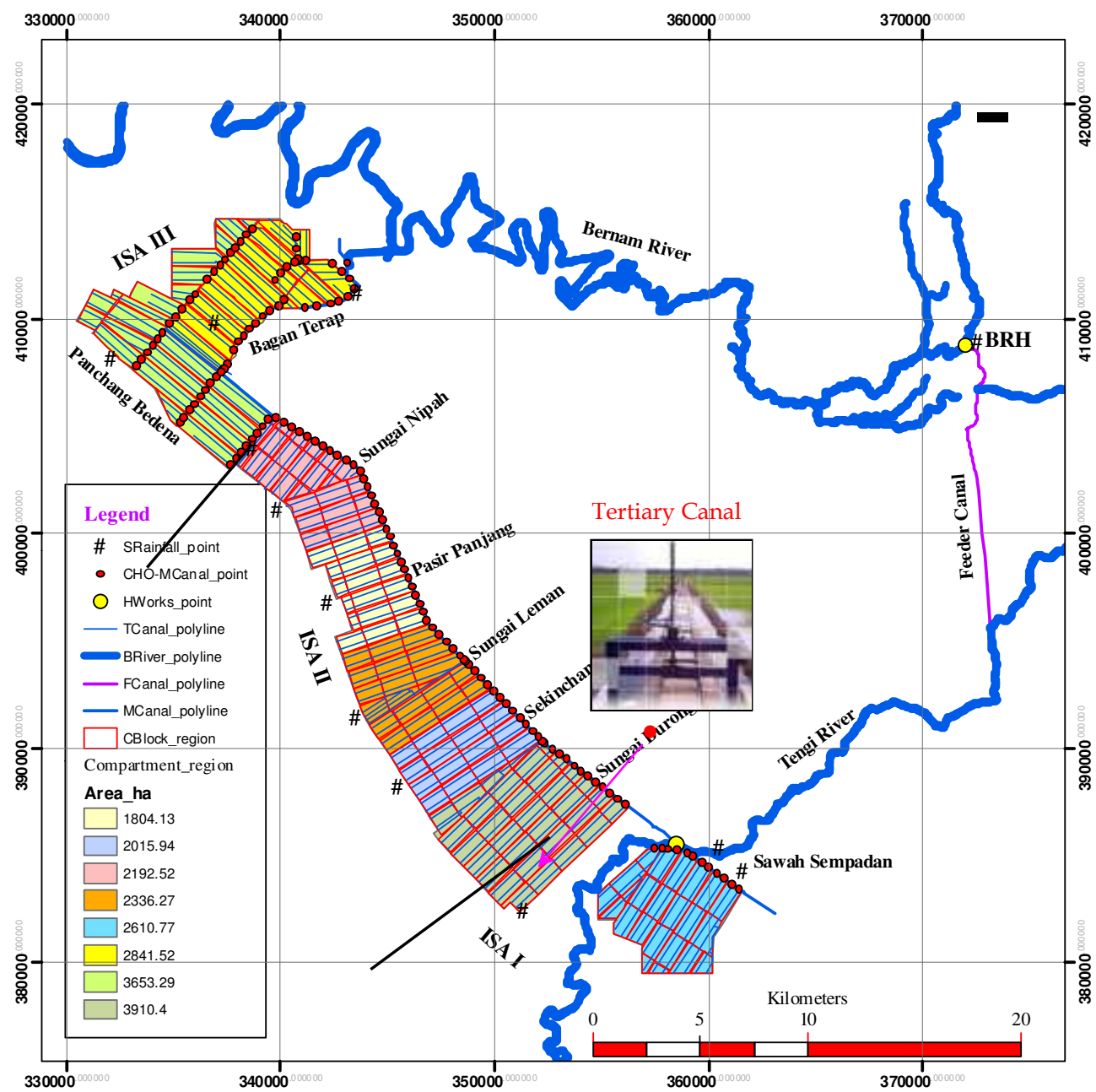

Fig. 1. Irrigation Distribution Network in the 18,000 ha Tanjung Karang Rice Irrigation Scheme (TAKRIS) Malaysia

\subsection{Data collection and GIS database development}

Many years of reliable climatic data records are required to estimate different parameters for a proper irrigation water management. Data and related information were obtained from 
relevant government agencies such as the Tanjung Karang Rice Irrigation Scheme Authority (IADA) for different ISAs, the Department of Irrigation and Drainage (DID), Department of Agriculture (DOA), Department of Survey and Mapping Malaysia (JUPEM) and Malaysia Meteorological Department (MMD). The detailed configuration of the irrigation canals, irrigation head regulator, Constant Head Orifice $(\mathrm{CHO})$ offtake structures and specifications, stage and discharge data for the main canal were obtained from the Irrigation and Drainage Authority of the Scheme and also from the DID Headquarters, Malaysia. Database development is the crucial task to bring all the information obtained into a GIS database. All the data were properly registered and assembled in GIS platform.

\subsection{Water demand estimation}

Water demand estimation is the primary considerations for planning, design and evaluating of the irrigation scheduling of a scheme. In Malaysia, the recommended design presaturation and supplementary irrigation requirements for the rice irrigation systems are $2.31 \mathrm{l} / \mathrm{s} / \mathrm{ha}(20 \mathrm{~mm} /$ day $)$ and $1.16 \mathrm{l} / \mathrm{s} / \mathrm{ha}(10 \mathrm{~mm} /$ day $)$, respectively. The total water requirement for rice production is about $1000-1500 \mathrm{~mm}$ depending on characteristics of the schemes. A quantitative estimation of the major components of field water balance provides management decisions on how the scheme ought to be operated to ensure better distribution of irrigation water and the delivery performance.

\subsubsection{Presaturation irrigation requirements}

A huge amount of water is consumed to inundate fields for presaturation before planting of the crop. The water required during presaturation period can be determined as follows:

$$
\mathrm{SAT}=\frac{\mathrm{IR}_{\mathrm{LS}}+\mathrm{EP}_{\mathrm{S}}+\mathrm{SP}+\mathrm{SW}}{I E}
$$

Where,

SAT $=$ water requirement during presaturation period $(\mathrm{mm} /$ day $)$

$\mathrm{IR}_{\mathrm{LS}}=$ water requirement to saturate the soil $(\mathrm{mm} /$ day)

$\mathrm{EP}_{\mathrm{s}}=$ evaporation loss from saturated soil surface $(\mathrm{mm} /$ day)

$\mathrm{SP}=$ seepage and percolation losses ( $\mathrm{mm} /$ day)

$\mathrm{SW}=$ additional supply to maintain the initial depth of flooding ( $\mathrm{mm} /$ day)

$\mathrm{IE}=$ overall irrigation efficiency

\subsubsection{Normal irrigation requirements}

The required irrigation water during the normal irrigation period shall be allocated on the basis of the equation (2):

$$
\mathrm{GIR}_{\mathrm{j}}=\frac{\left(E T_{\mathrm{O}}\right)_{j} \times \mathrm{K}_{\mathrm{c}}+\mathrm{SP}_{\mathrm{j}}-\mathrm{ER}_{\mathrm{j}}}{\mathrm{IE}}
$$

where,

$\mathrm{GIR}_{\mathrm{j}}=$ gross irrigation water requirement $(\mathrm{mm} /$ day $)$

$\left(\mathrm{ET}_{0}\right)_{\mathrm{j}}=$ reference crop evapotranspiration $(\mathrm{mm} /$ day) 
$\mathrm{SP}_{\mathrm{j}}=$ seepage-percolation loss ( $\mathrm{mm} /$ day)

$\mathrm{ER}_{\mathrm{j}}=$ effective rainfall $(\mathrm{mm} /$ day $)$

$\mathrm{K}_{\mathrm{c}}=$ crop coefficient

$\mathrm{IE}=$ overall irrigation efficiency, which is assumed to be $45 \%$, [14].

For presaturation water depth, the DID recommendation of $20 \mathrm{~mm} /$ day is used. This would help to maintain the standing water depth of $100 \mathrm{~mm}$ for the normal irrigation period. The minimum standing water depth $\left(\mathrm{SW}_{\min }\right)$ is maintained at $50 \mathrm{~mm}$. The seepage-percolation (SP) rate of 2-3 mm/day is considered throughout the growth period [14 and 15].

If part of the water requirement is met by utilization of rainfall during crop growing period, then the net irrigation requirement on a particular day is determined as:

$$
\mathrm{NIR}_{j}=\mathrm{ET}_{\mathrm{j}}+\mathrm{SP}_{\mathrm{j}}-\mathrm{ER}_{\mathrm{j}}+\mathrm{SW}_{\mathrm{j}}-\mathrm{SW}_{\mathrm{j}-1}
$$

where, $\mathrm{ET}_{\mathrm{j}}$ is $\mathrm{ETo}_{\mathrm{j}}{ }^{*} \mathrm{kc}, \mathrm{SW}_{\mathrm{j}}$ is the required standing water depth for a particular day, and $S W_{j-1}$ is field water level at the beginning of irrigation supply on (j-1)-th day. The $\operatorname{NIR}_{\mathrm{j}}$ is determined as in Equation 3 when paddy fields remain in the condition $S W_{j} \geq S W_{j-1}$. However, this condition is rare during peak water demand and it is possible only by storing a significant amount of rainfall in the paddy fields. The inequality between $S W_{j}$ and $\mathrm{SW}_{\mathrm{j}-1}$ leads to different water balance scenarios as well as water allocation rules, which are determined mainly by $\mathrm{SW}_{\mathrm{j}-1}$ that falls short or exceeds the required standing water depth. The conditions for the estimation of the net irrigation requirements are summarized in Table 1.

\begin{tabular}{|c|c|l|}
\hline $\begin{array}{c}\text { Water balance } \\
\text { condition }\end{array}$ & $\begin{array}{c}\text { Availability of irrigation } \\
\text { supply condition with respect } \\
\text { to demand }\end{array}$ & \multicolumn{1}{c|}{ Net irrigation requirements $\left(\mathrm{NIR}_{\mathrm{j}}\right)$} \\
\hline $\mathrm{SW}_{\mathrm{j}}=\mathrm{SW}_{\mathrm{j}-1}$ & $\mathrm{Q}_{\mathrm{rs}}>\mathrm{Q}_{\mathrm{ar}} \leq \mathrm{Q}_{\mathrm{av}}$ and $\mathrm{ER}_{\mathrm{j}}=0$ & $\begin{array}{l}\mathrm{NIR}_{\mathrm{j}}=\mathrm{ET}_{\mathrm{j}}+\mathrm{SP}_{\mathrm{j}}-\mathrm{ER}_{\mathrm{j}} \\
\mathrm{NIR}_{\mathrm{j}}=0 \text { and } \mathrm{SW}_{\mathrm{j}}=\left(\mathrm{SW}_{\mathrm{min}} \leq \mathrm{SW}_{\mathrm{adj}}<\mathrm{SW}_{\mathrm{j}}\right)\end{array}$ \\
\hline $\mathrm{SW}_{\mathrm{j}}<\mathrm{SW}_{\mathrm{j}-1}$ & $\mathrm{Q}_{\mathrm{rs}} \leq \mathrm{Q}_{\mathrm{av}}$ & $\begin{array}{l}\mathrm{NIR}_{\mathrm{j}}=0 \\
\mathrm{Q}_{\mathrm{rs}}>\mathrm{Q}_{\mathrm{av}} \text { and }\left(\mathrm{ET}_{\mathrm{j}}+\mathrm{SP}_{\mathrm{j}}\right) \neq \mathrm{ER}_{\mathrm{j}}\end{array}$ \\
\hline $\mathrm{NIR}_{\mathrm{j}}=0$
\end{tabular}

Table 1. Net Irrigation Requirements for Different Water Balance Scenarios

\subsection{Assessment of the irrigation delivery performance for rice}

Indicators and measures of irrigation water delivery performance are best when those can be used to evaluate the irrigation delivery performance and as management tool to keep track of the water delivery performance as the season progresses. In this regards, the RWS concept is appropriate and can be applied for paddy rice and upland rice or other crops. This discussion however is restricted mainly to paddy rice for characterizing the irrigation delivery performance using the RWS concept. 


\subsubsection{Relative water supply (RWS) concept}

The available water supply and the water demand are the two most crucial factors for planning, design and operation of any irrigation system. The ratio of supply and demand constitutes an important concept called the Relative Water Supply [6]. This concept is actually the inverse of the engineering irrigation efficiency, output over input. The irrigation supply is the supply measured at the point of interest. The total water supply is defined to include both the irrigation supply and the effective rainfall during the period being considered. The effective rainfall is the fraction of the total rainfall over the irrigation command area that potentially could substitute for the irrigation supply. The total water demand is considered from losses due to crop evapotranspiration and seepage-percolation for the same duration. The RWS is mathematically expressed as follows:

For land preparation period or pre-saturation period,

$$
R W S_{j}=\frac{I R_{j}+E R_{j}}{E P_{j}+S P_{j}+L S_{j}}
$$

For normal crop growth period,

$$
R W S_{j}=\left(\frac{I R_{j}+E R_{j}}{E T_{j}+S P_{j}}\right)
$$

where, $\mathrm{LS}_{\mathrm{j}}=$ Land soaking water requirement in $\mathrm{cm}$. The lower bound of RWS $=1.0$ and the higher bound of RWS $=1.15$ or more considered as the management strategy to maintain adequate water supply [7]. For any period, the value less than 1.0 represents undersupply and the value more than the upper bound represents oversupply. In fact, the upper bound value is not standard for characterizing the irrigation delivery as it depends on many factors involved in the irrigation systems. The RWS value can be maintained at lower bound level considering the expected stochastic rainfall in the next irrigation period. If no rainfall occurred, the paddy fields will remain undersupplied.

The RWS concept has proven to be a useful tool for understanding the performance of the irrigation systems and the impact on performance of the behavior of the major participants (the irrigation engineers and the farmers) in the irrigation process. It is useful for analysis and interpretation of irrigation performance for different time intervals and for different locations at system and sub-system levels. The computation flexibility in terms of time and space of the RWS makes it easy to use for evaluating the irrigation delivery performance. In addition to the potential for evaluating irrigation performance, the RWS concept is useful to evaluate the relative equity of water service with a system. It has also proven useful in understanding the decision rules that characterize system operation.

Traditionally rice is grown under continuous submergence or intermittent or variable ponding conditions depending on the farmer's choice and also on the water resources. This is the basic difference for the rice irrigation management system from other crops. Some additional water is required to maintain the standing water depth in the field due to the difference between the Desired or Maximum Standing Water Depth $\left(\mathrm{WSmax}_{\mathrm{j}}\right)$ and the Present Standing Water Depth $\left(\mathrm{WS}_{\mathrm{j}}\right)$. The widely used Relative Water Supply (RWS) concept 
gives incorrect determination to characterize an oversupply condition on irrigation deliveries for not considering this additional water supply for rice production.

\subsubsection{Rice Relative Water Supply (RRWS)}

The Rice Relative Water Supply (RRWS $)_{j}$ is defined as the ratio of the total supply as Irrigation requirement $\left(\mathrm{IR}_{\mathrm{j}}\right)$ and Effective Rainfall $\left(\mathrm{ER}_{\mathrm{j}}\right)$ to the total demand as the sum of the difference between Maximum Ponding Water Depth and Present Ponding Water Depth $\left(W_{S m a x}-W S_{j}\right)$ for a particular irrigation period; Evapotranspiration $\left(E_{j}\right)$ and SeepagePercolation $\left(\mathrm{SP}_{\mathrm{j}}\right)$ in the service areas for a duration being considered. It can distinctly characterize the oversupply for RRWS $>1.0$ and undersupply for $R R W S_{j}<1.0$ for any given period as the season advances. The value of $R R W S_{j}=1.0$ indicates irrigation supply is perfectly matched with the field water demand. Incorporating depleted ponding water $\left(W S m a x_{j}-W S_{j}\right)$ into eq. (6) is the modification for the RWS concept given by [6] especially useful for evaluating irrigation delivery in rice-based systems. The RRWS is expressed as follows:

$$
\operatorname{RRWS}_{j}=\frac{\mathrm{IR}_{\mathrm{j}}+\mathrm{ER}_{\mathrm{j}}}{\left(\mathrm{WSmax}_{\mathrm{j}}-\mathrm{WS}_{\mathrm{j}}\right)+\mathrm{ET}_{\mathrm{j}}+\mathrm{SP}_{\mathrm{j}}}
$$

The oversupply and undersupply can be simply identified for any given irrigation period with the actual RRWS value compared to the RRWS $=1.0$. For a particular period, irrigation supply is gradually increased with the amount of depleted ponding water until it reaches the maximum level in the field. Without considering this amount, RWS gives higher values, which are normally characterized as the false oversupply condition. In fact, it is not necessarily an oversupply. A value of RWS $=0.8$ may not represent a problem, rather it may provide an indication that farmers are practicing deficit irrigation supply to maximize returns on water [16]. This remark can be adopted for operating irrigation system even at RRWS $=0.5$ for a particular period to overcome water shortage and could be helpful to store more rainfall if WSmax $\mathrm{j}$ is retained.

\subsubsection{Cumulative Rice Relative Water Supply (CRRWS)}

The Cumulative Rice Relative Water Supply (CRRWS) is defined as the accumulated value of RRWS, which is the ratio of supply to the demand computed over short intervals of time starting from a particular time of the season. The advantage of CRRWS is similar throughout the season like CRWS. In addition, CRRWS can overcome the weakness of RWS and CRWS. It can be defined for a particular period as follows:

$$
\text { CRRWS }_{j}=\sum_{j=1}^{n} \frac{I R_{j}+E R_{j}}{\left(W \max _{j}-W S_{j}\right)+E T_{j}+S P_{j}}
$$

The slope and the trend of the CRRWS concept provide useful management inferences simpler than CRWS. The values of CRRWS for daily, weekly or any other short interval of cropping season with time interval can be plotted along the x-axis and CRRWS value along the Y-axis. This plot carries with the curve designated as CRRWS $=1.0$. If computed CRRWS line follows the CRRWS $=1.0$ line, it means that irrigation deliveries are entirely matched 
with the field water demand for a particular irrigation period. An increasing slope of the actual CRRWS curve with CRRWS $=1.0$ means that irrigation supply can be slightly curtailed in the next period. On the other hand, if the slope is downwards, supply has to be increased.

\subsubsection{Ponding Water Index (PWI)}

The Ponding Water Index is the relation between present and the maximum desired ponding water depth for the duration being considered. It indicates the state of the water deliveries for a specific period with respect to the desired ponding water depth in the field during the crop growing season. It can be expressed as the following equation:

$$
\mathrm{PWI}_{\mathrm{j}}=\frac{\mathrm{WS}_{\mathrm{j}}-\mathrm{WSmax}_{\mathrm{j}}}{W \mathrm{Wmax}_{\mathrm{j}}}
$$

Where

$W S_{j}$ is the measured ponding water depth on $j$-th day

$\mathrm{WSmax}_{\mathrm{j}}$ is the maximum desired ponding water depth on $\mathrm{j}$-th day

The WSmax ${ }_{\mathrm{j}}$ is normally varied from 2 to $10 \mathrm{~cm}$ during the crop growth periods. For achieving good irrigation water delivery performance and efficient water management, the $\mathrm{PWI}_{j}$ is recommended to be maintained at $-1.0>\mathrm{PWI}_{j} \leq 0$. Ponding Water Index gives the following interpretation over periodic irrigation supply at the end of a period:

$$
\begin{gathered}
\mathrm{PWI}_{\mathrm{j}}>0 \text { Over supply condition } \\
\mathrm{PWI}_{\mathrm{j}}=0 \text { Well-watered condition } \\
\mathrm{PWI}_{\mathrm{j}}=(-\mathrm{ve}) \text { Under supply } \\
\mathrm{PWI}_{\mathrm{j}}=-1.0 \text { Critical or saturation condition. }
\end{gathered}
$$

The $\mathrm{PWI}_{\mathrm{j}}$ gives distinct scenarios whether irrigation supply could be supplied properly or not during the crop growth periods. It gives the useful information for irrigation management decisions to managers. The indicator can also quantify the amount of undersupply with respect to maximum desired ponding water depth at the field level for the week being considered.

\subsection{ArcGIS user-interface and operation procedures}

Rice Irrigation Management Information System (RIMIS) with delivery performance assessment tool was developed for the Tanjung Karang Rice Irrigation Scheme as a userfriendly interactive system. RIMIS is an ArcGIS-VBA user-interface with many sub-modules and functions within the powerful ArcGIS environment. On activation of ArcGIS Software, the menu "RIMIS" appears directly on the Menu Bar in the ArcMap Window (Fig. 2). On clicking the Command Button, "Irrigation Delivery Performance" in Fig. 2, the Dialog Wizard for irrigation delivery performance will appear. RIMIS allows the irrigation manager to run the day-to-day operation and management activities as the season advances. The program is used to characterize the daily irrigation water allocation scenario and to 
evaluate the irrigation delivery performance using the selected performance indictors as the season advances.

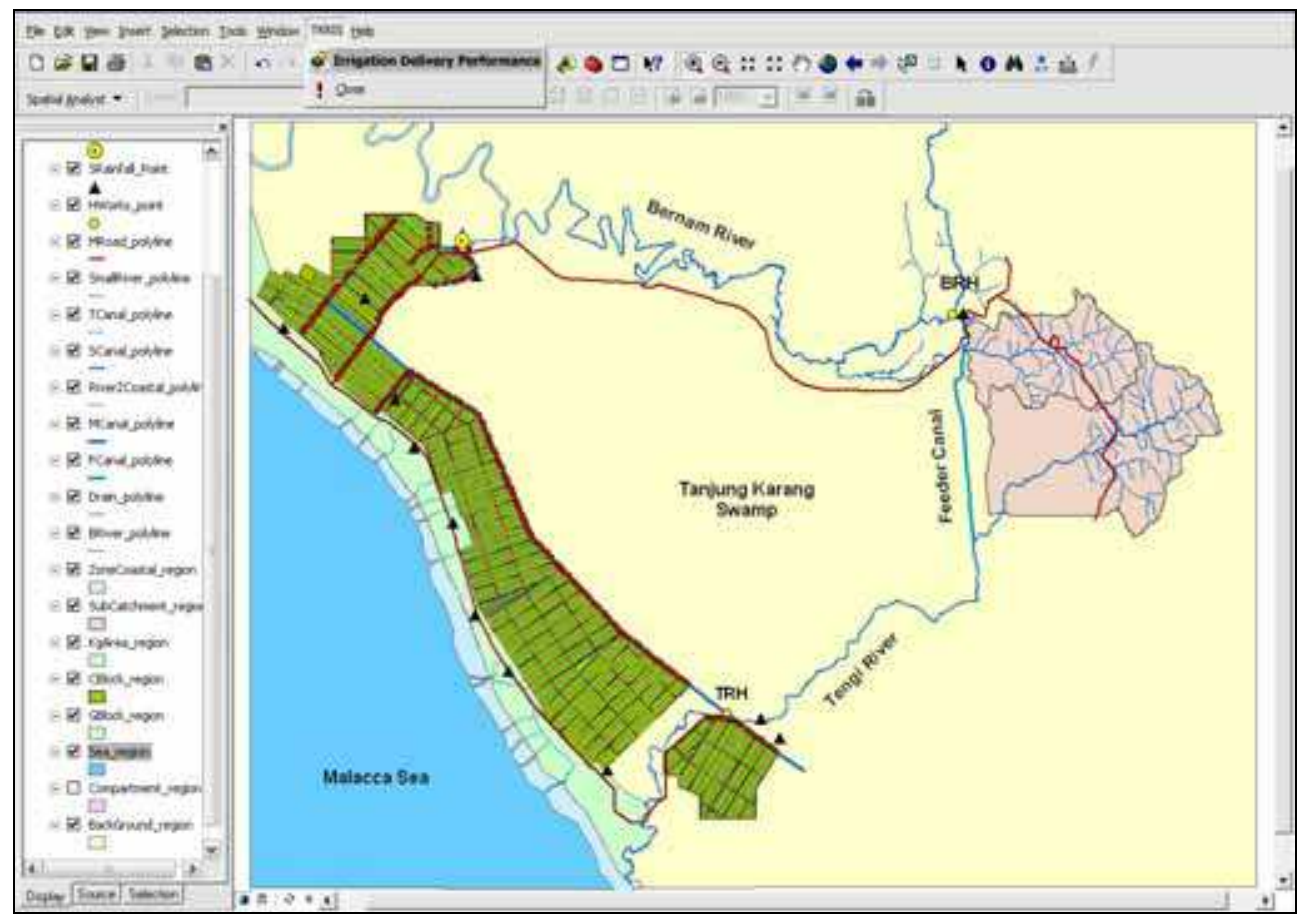

Fig. 2. The RIMIS Menu for the Tanjung Karang Rice Irrigation Scheme (TAKRIS) in ArcGIS

The user needs to enter the required inputs and choose the appropriate command button to view the results. Inputs can be directly fed into the dialog window by clicking on the command button "Data from Input Files" or manually (Fig. 3). All required inputs stored in Input Files are instantly retrieved into TextBoxes by each irrigation service area i.e. "ISAI: Input Daily Information (I)". Command Buttons for new irrigation delivery performance indicators, Rice Relative Water Supply (RRWS), Cumulative Rice Relative Water Supply (CRRWS) and Ponding Water Index (PWI) together with the Relative Water Supply (RWS) concept are shown in Fig. 3. Users may feed accurate information from other sources manually if available and reliable. To compute the performance indicators correctly, users should enter the actual information of rainfall and reference crop evapotranspiration on the day as they are available at the end of the irrigation day. A sub-routine was developed to compute the daily potential crop evapotranspiration as shown in Figures $4 \mathrm{a}$ and $4 \mathrm{~b}$. This sub-module allows an irrigation manager to compute the daily Reference Crop Evapotranspiration (ETo) using the Internationally recommended FAO Penman-Montieth Equation based on the available climatic information for a particular day. However studies by Hassan (2006) show that ETo calculated by the Penman-Montieth Equation gives an underestimation of ETo by $10 \%$ compared to ETo from micro-lysimeters installed in the paddy fields. 
The system allows for storing of all inputs and outputs into the MS Access database simply by clicking on the Command Button "Save". It has also capabilities of retrieving, editing, deleting records from database for a particular day upon selection. The Command Button "Backup" helps to keep all files as backup any time. The dialog wizard linked with the Command Button "View Inputs \& Outputs" in Fig. 3 allows interactive viewing for all input and output databases. It enables to users viewing data in table and graph formats. The records of the selected table are displayed. The records from the selected Table can be viewed for a specified duration and the selected fields. The easily obtained comprehensive information allows the manager to characterize the irrigation delivery performance faster. The dialog wizard for exploring the scheme's information can also be viewed on clicking the command button "Detailed Scheme Information" in Fig. 3. This sub-module gives salient features of the scheme in the form of maps, graphs and tabular formats.

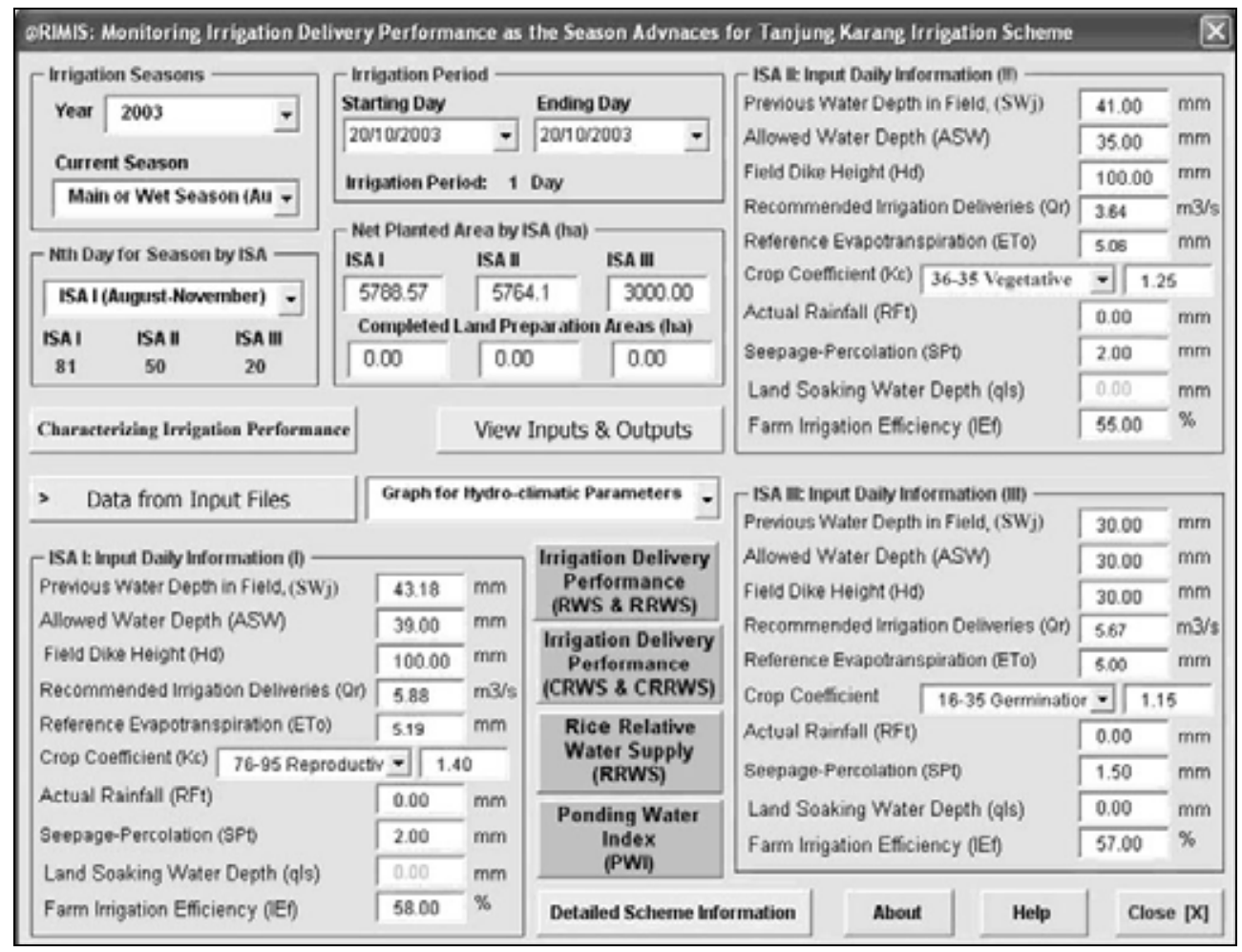

Fig. 3. Dialog Wizard for Characterizing Irrigation Delivery Performance for the Main Season

\subsection{Results and discussions}

To adopt proper irrigation supplies, the appropriate information system is a prerequisite to make the right decision on water allocation as well as possible remedial actions as the season advances. Typical results produced using the GIS based assessment tool is presented in the following sections for visualization in colored maps, charts and tables as the season 


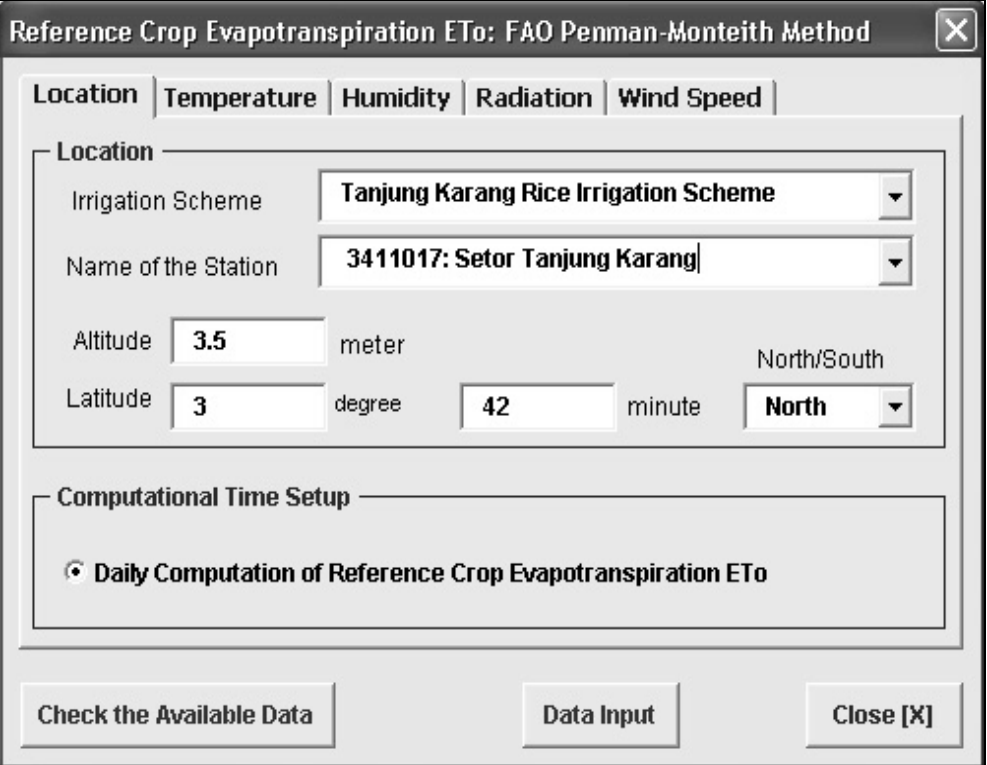

(a) Input Selection Dialog Wizard

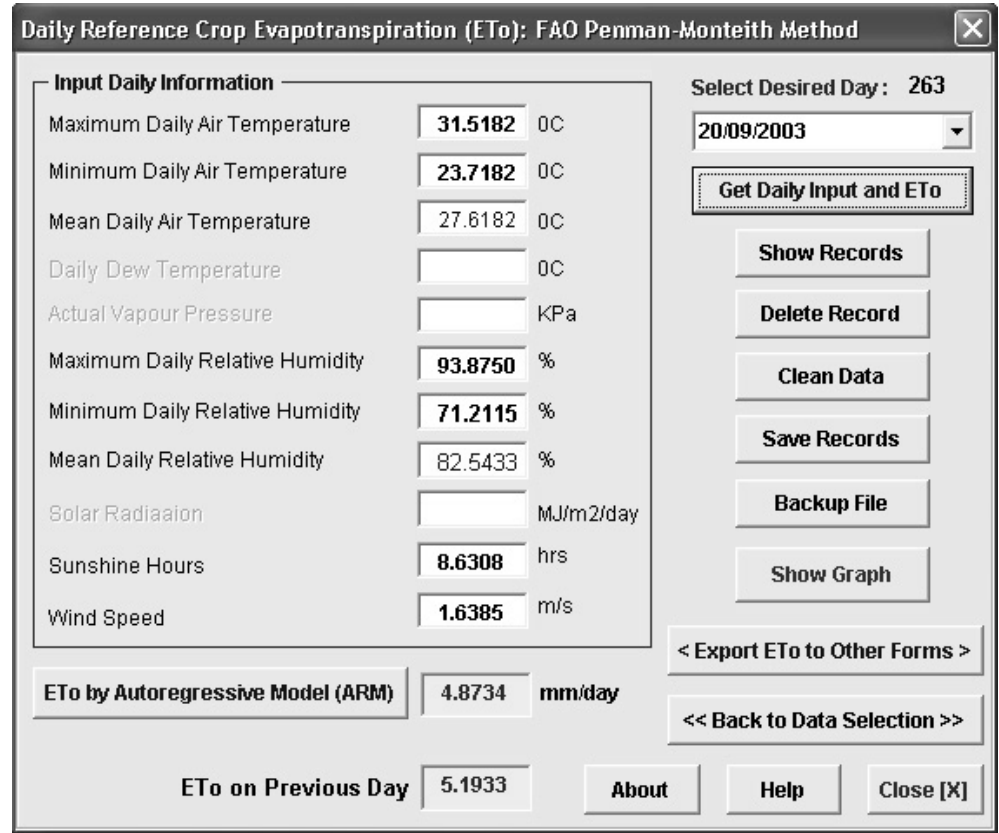

(b) Input Dialog Wizard for Daily Meteorological Data

Fig. 4. Computing Daily $\mathrm{ET}_{\mathrm{o}}$ using FAO Penman-Monteith Method 
advances. The system provides useful information of the actual field condition with respect to the water demand as the season progresses and helps allocate the right amount of irrigation supplies for the next day or period.

\subsubsection{Characterizing irrigation delivery performance}

The characterization is essential to evaluate irrigation deliveries among tertiary canals and for their remedial measures as the season advances. A dialog wizard like that in Fig. 3 appears by clicking on the Menu Item "Irrigation Delivery Performance" in the dialog wizard shown in Fig. 3. To get the output, the user needs to enter the required inputs and the appropriate options. Inputs are directly fed from the input database by clicking on the Command Button "Data from Input Files" or manually. After that, the results for a particular day can be computed and viewed on a screen instantly like that shown in Fig. 5 by clicking on the Command Button "Monitoring Irrigation Performance" in Fig. 3. New performance indicators RRWS and PWI are used for evaluating and characterizing irrigation delivery performance and compared the advantages and disadvantages with the RWS concept especially for paddy irrigation system. The 18,000 ha irrigation scheme is divided into 3 Irrigation Service Areas (ISA) with a staggered supply of one month.

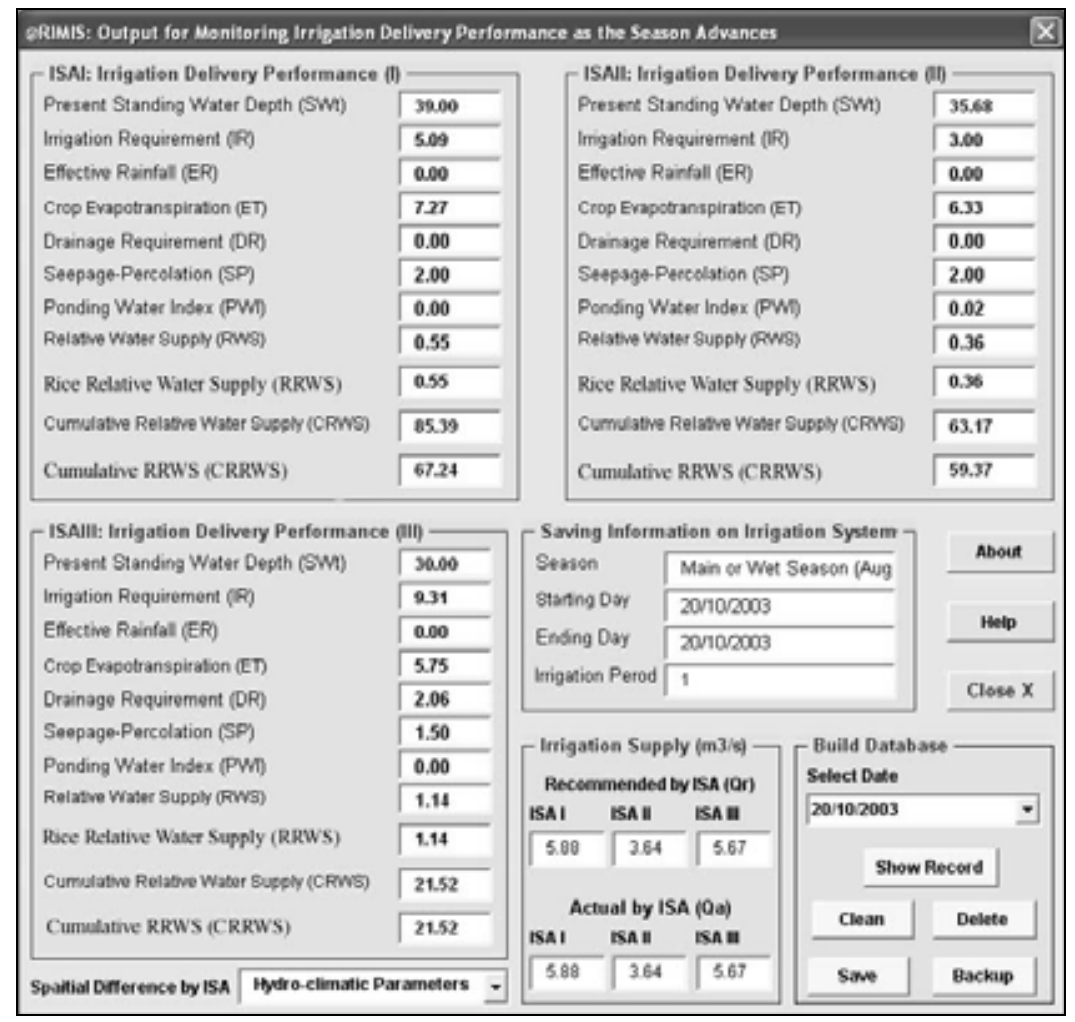

Fig. 5. Output Dialog Window for Characterizing Irrigation Delivery Performance on 20 October 2003 
The irrigation performance characterizes as over supply for RRWS $>1.0$, undersupply for RRWS $<1.0$ and good performance for RRWS $=1.0$. Therefore, the irrigation manager can easily quantify how irrigation water ought to be allocated with the available water resources for the next day or irrigation period.

\subsubsection{Rice Relative Water Supply (RRWS)}

After clicking on the Command Button "Rice Relative Water Supply (RRWS)" in Fig. 3, irrigation delivery performances from the beginning to the current days for the current irrigation season are plotted as shown in Fig. 6. The irrigation performance characterizes as over supply for RRWS $>1.0$, undersupply for RRWS $<1.0$ and good performance for RRWS $=1.0$. Therefore, the irrigation manager can easily quantify how irrigation water ought to be delivered with respect to the available water resources for the next day.

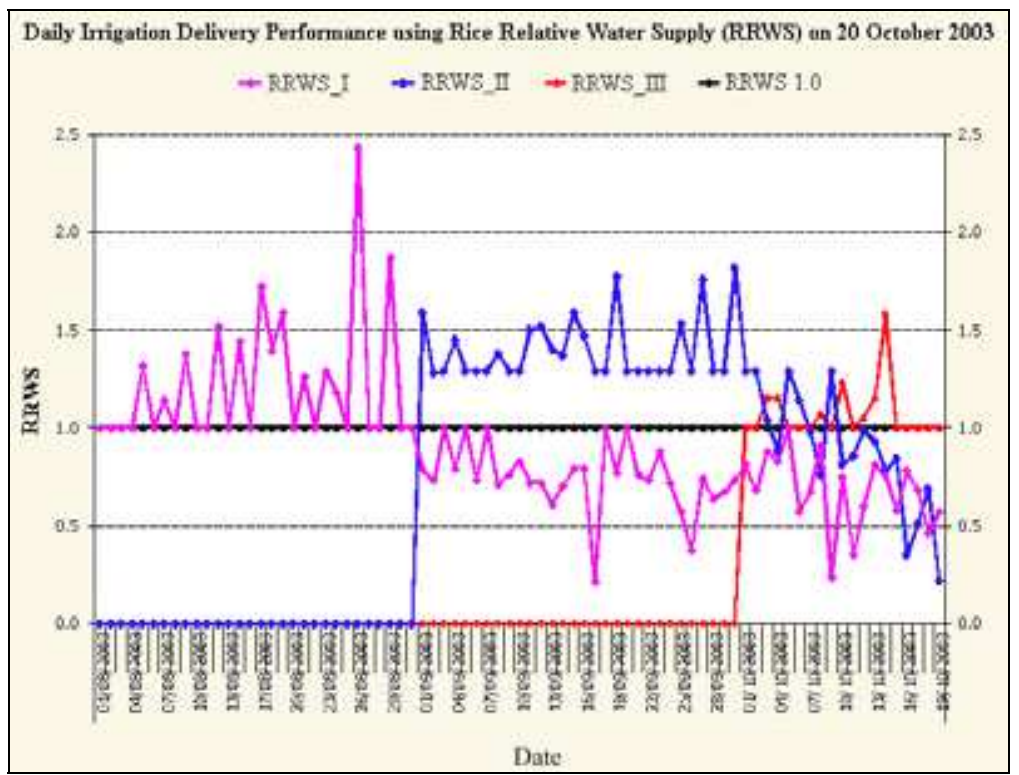

Fig. 6. Characterizing Daily Irrigation Delivery Performance using RRWS for Main Season 2003

The RRWS_I, RRWS_II and RRWS_III represent Rice Relative Water Supply for Irrigation Service Areas I, II and III where irrigation supply is staggered by one month, respectively. From Fig. 6, the following decisions can be drawn (Table 2):

\begin{tabular}{|c|c|c|c|}
\hline \multirow{2}{*}{ Month } & \multicolumn{3}{|c|}{ Irrigation Delivery Conditions by ISA } \\
\cline { 2 - 4 } & ISA I & ISA II & ISA III \\
\hline August & Oversupply & No Supply & No Supply \\
\hline September & Under Supply & Oversupply & No Supply \\
\hline October & Oversupply & Under Supply & Under Supply \\
\hline
\end{tabular}

Table 2. Characterization of Irrigation Delivery Conditions 
From this scenario, it is noticed that oversupply conditions were found only during the presaturation period in the first month for each ISA. Undersupply condition was found during the normal irrigation supply for all ISAs. If irrigation supply would follow the RRWS guideline, then it could be possible to overcome the oversupply and undersupply conditions. If irrigation supplies would be curtailed for the ISA II and increase for the ISA I then irrigation delivery might have maintained good conditions as shown in the middle of the plot in Fig. 6 .

\subsubsection{Cumulative Rice Relative Water Supply (CRRWS)}

The Cumulative Rice Relative Water Supply (CRRWS) values were plotted for both seasons of 2003/04 as shown in Figs. $7 \mathrm{a}$ and $7 \mathrm{~b}$. These plots have three other curves designated as CRRWS $=1.0$ staggered by one month. The relative merits and demerits between the plots CRWS and CRRWS have brought the robustness of using the new indicators for evaluating irrigation delivery performance as the season advances. The slope of the actual CRRWS curve provides useful management information, which can enhance the decision-making for the irrigation delivery. If there is an increasing slope of CRRWS line with respect to the CRRWS $=1.0$ line then irrigation supply could be slightly curtailed in the next irrigation period. On the other hand, if the slope is downwards and is reaching the lower CRRWS = 1.0 line, the supply could be increased for the next irrigation period. The coinciding between actual CRRWS and CRRWS $=1.0$ lines characterizes well water distribution. The CRRWS plot should be maintained at the CRRWS $=1.0$ to improve irrigation delivery performance.

The CRRWS_I, CRRWS_II and CRRWS_III represent Cumulative Rice Relative Water Supply (CRRWS) for Irrigation Service Area (ISA) I, II and III, respectively. In Fig. 6a, the CRRWS values obtained higher than 1.0 during the land preparation periods in ISA I, ISAII and ISA III but lower at normal irrigation periods in ISA I. The slope of CRRWS line of ISA I decreased when land preparation was started in ISA II and the slope of CRRWS line of ISA II decreased after starting the land preparation in ISA III due to water shortage in the offseason. The plot for all irrigation service areas are shown normally under supply condition after completing land preparation in ISA I from May.

In the Fig. $7 \mathrm{~b}$, the CRRWS values obtained were higher than 1.0 during the land preparation periods in ISA I, ISAII and ISA III but lower at normal irrigation periods in ISA I. The slope of CRRWS line of ISA I started to decrease when land preparation was started in ISA II and the slope of CRRWS line of ISA II decreased after starting the land preparation in ISA III in the main season. The irrigation supplies for all irrigation service areas were not shown under supply condition throughout the irrigation season. The slope of the CRRWS line for ISA III shows better irrigation delivery performance than ISA and ISA II. The plot shows that available water resources could not meet field water demand at the design ponding water level $10 \mathrm{~cm}$ during normal irrigation periods. The utilization of rainfall plays an important role to maintain target standing water depth in the fields. The oversupply conditions were normally found on rainy days.

\subsubsection{Ponding Water Index (PWI)}

A daily analysis of Ponding Water Index (PWI) was plotted for the main and off seasons in 2003/04 as shown in Fig. 8. The PWI_I, PWI_II and PWI_III represent Ponding Water Index 


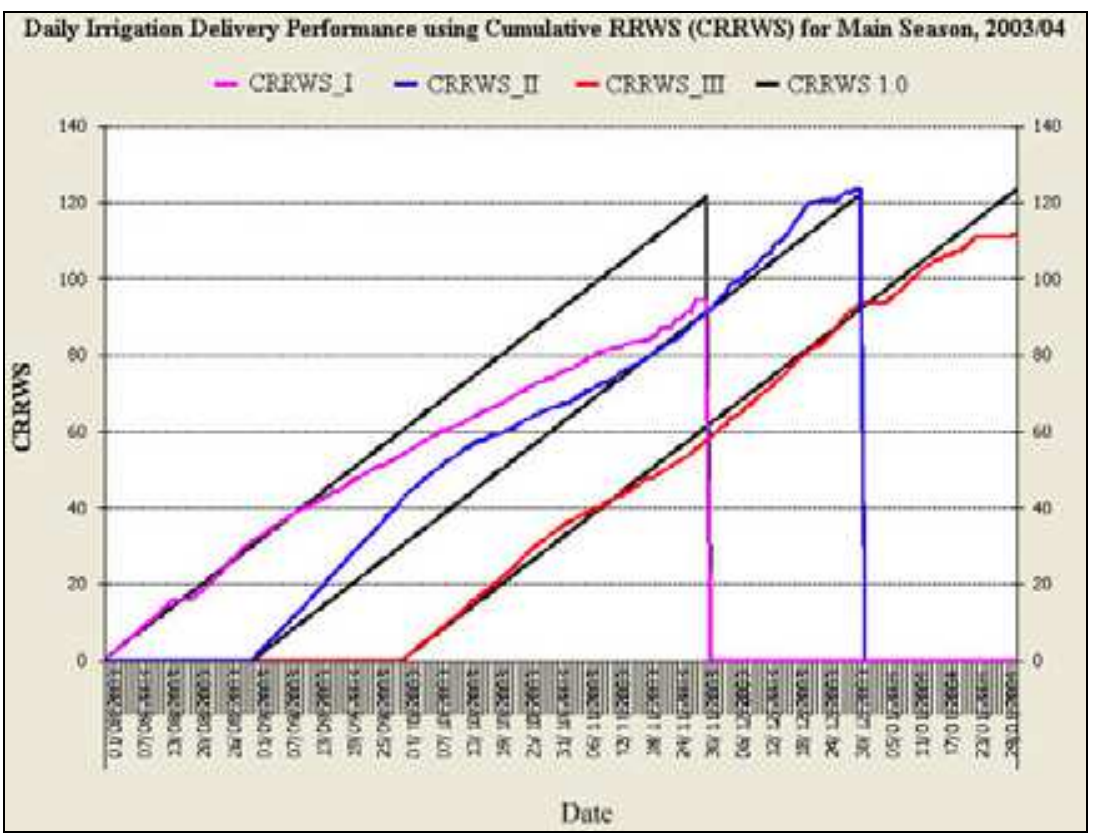

(a) Main Season in 2003/04

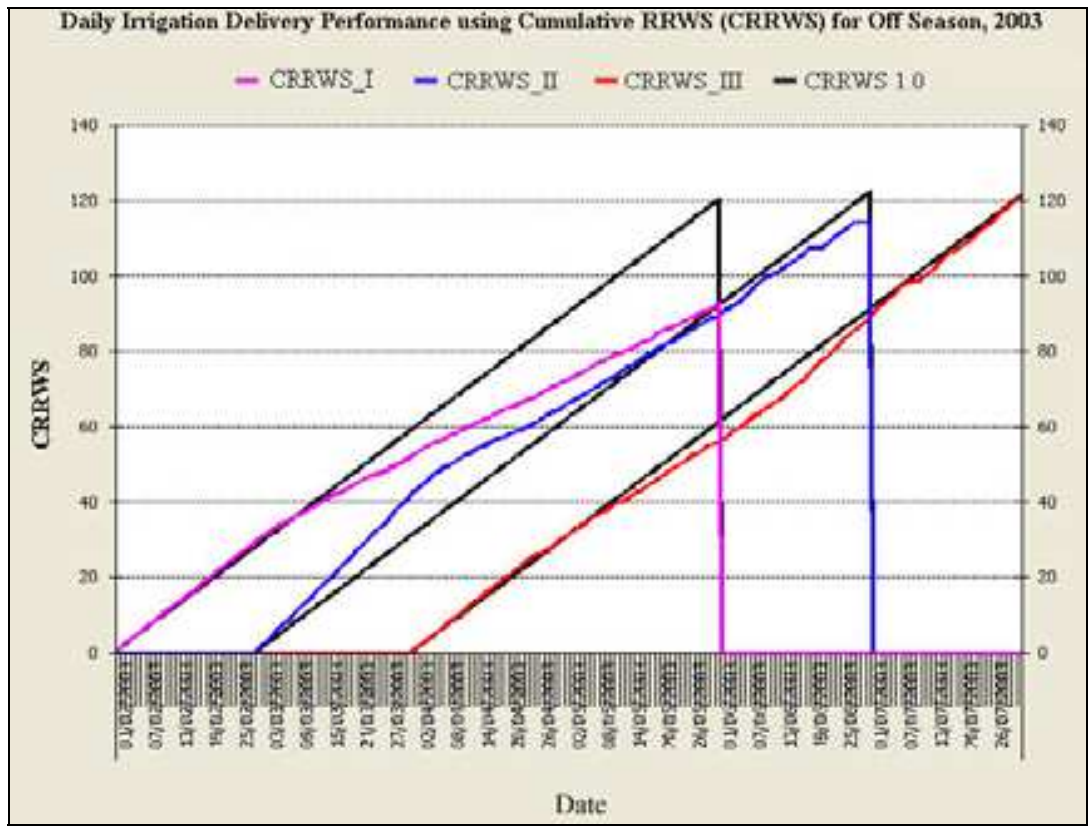

(b) Off Season in 2003/04

Fig. 7. Characterizing Daily Irrigation Delivery Performance using CRRWS 
(PWI) for Irrigation Service Area (ISA) I, II and III, respectively. The undersupply condition was obtained due to shortage of water resources. The extreme values computed due to continuing irrigation deliveries while sufficient water remained in the fields. The oversupply condition is shown during land preparation period and especially rainy days. The peak negative values are due to severe shortage of water.

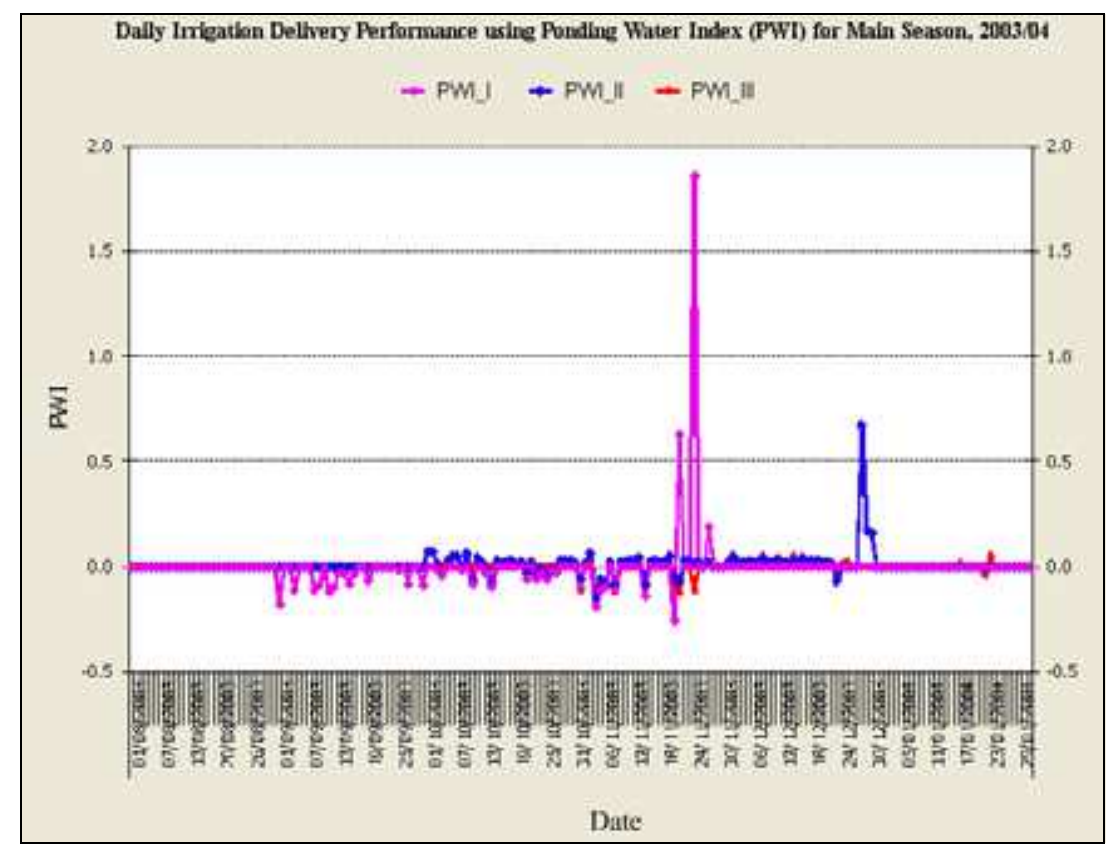

Fig. 8. Characterizing Daily Irrigation Delivery Performance using Ponding Water Index (PWI) for the Main Season in 2003/04

Irrigation deliveries have shown oversupply due to more rainfall from 20-24 November and end of the season in the main season. The days on the x-axis at zero value shows the wellwatered condition. Irrigation deliveries will be considered as over supply or under supply if PWI is more or less than zero, respectively. The irrigation manager can simply identify and quantify the performance of irrigation deliveries for a given day and what decision has to be made for the next period. Both the PWI and RRWS can quantify and identify irrigation deliveries simultaneously. The average variation of the PWI values is higher in the off season than in the main season. The PWI also represents under supply condition in the off season as more severe than in the main season. Besides, the values of PWI are very close to $\mathrm{PWI}=0$ for the main season. The peak values are shown due to heavy rainfall.

\subsection{New water management tool}

This book chapter illustrates new irrigation performance indicators known as the Rice Relative Water Supply (RRWS) and Cumulative Rice Relative Water Supply (CRRWS) to evaluate irrigation water delivery performance of the paddy rice irrigation systems. The 
weakness of using the Relative Water Supply (RWS) and Cumulative Relative Water Supply (CRWS) and its adverse implications on irrigation management and operation was also highlighted. Each performance indicator has its own strengths and weaknesses, which may be relevant under particular conditions. The RRWS and CRRWS parameters instead of RWS and CRWS were found to be more useful for the irrigation managers and water users to characterize the water delivery performance for the paddy irrigation systems.

The following conclusions can be drawn from the study on performance indicators:

The RRWS and CRRWS can simply and distinctly characterize irrigation delivery performance with respect to the RRWS = 1.0. It gives the following interpretation over periodic irrigation supply at the end of a period:

$$
\begin{gathered}
R_{R W S_{j}}=1.0 \text { Good irrigation delivery } \\
\text { RRWS }_{\mathrm{j}}>1.0 \text { Oversupply condition } \\
\text { RRWS }_{\mathrm{j}}<1.0 \text { Undersupply condition }
\end{gathered}
$$

- The RWS $S_{\mathrm{j}}$ concept shows the over supply condition for not considering the depleted water depth $\left(W_{S m a x}-W_{j}\right.$ ) of the denominator in RWS given by Levin (1982) when $W S_{j}<W S m a x_{j}$ in the paddy fields.

- $\quad$ The utility of RRWS and CRRWS justify the weakness of RWS and CRWS to evaluate the irrigation water delivery for paddy irrigation systems.

- It recommends that irrigation supply should be curtailed for increasing the slope of the actual CRRWS line than the CRRWS $=1.0$ line to improve the irrigation delivery performance.

- Irrigation system can be operated even at RRWS $=0.5$ to irrigate wider areas due to water shortage if the Ponding water depth is retained more than the field water demand for the next period.

The Ponding Water Index (PWI) also can simply characterize irrigation delivery performance. It gives the following interpretation over periodic irrigation supply at the end of a period:

$$
\begin{gathered}
\mathrm{PWI}_{\mathrm{j}}=0 \text { Good irrigation delivery condition } \\
\mathrm{PWI}_{\mathrm{j}}>0 \text { Oversupply condition } \\
\mathrm{PWI}_{\mathrm{j}}<0 \text { Undersupply condition }
\end{gathered}
$$

The new indicators have successfully been evaluated for various water management scenarios in the study area. Therefore, they can be adopted to evaluate irrigation delivery performance and proper decision for water allocation for irrigated paddy. GIS interface coupled with new performance indicators has explicitly helped in integrating spatial and temporal information for evaluating the daily irrigation delivery performances for paddy cultivation. The new irrigation performance indicators are able to provide useful information and can be adopted to evaluate irrigation delivery performance and proper decision for water allocation in the paddy irrigation system. The availability of such a quantitative tool for irrigation systems operation can have a powerful impact on the overall water management strategy in an irrigation project area. 


\section{Precision farming of rice}

\subsection{Saving resources through precision farming}

Precision farming (PF) is considered the best practicable approach to achieve sustainable agriculture. Precision farming is an integrated, information- and production- based farming system that aims to raise efficiency, productivity and profitability of long term, site-specific and whole farm production while avoiding the undesirable effects of excessive chemical loading to the environment or insufficient input application.

The role of PF in crop production technology is recognized worldwide, but so far, it is applied mostly on large farms. Implementation of PF should be followed in three main steps of information gathering in terms of variability, data processing to evaluate the significance of variation and employ new management strategy to apply farming inputs. Fig. 9 demonstrates some equipment and technologies in a typical precision farming crop growing cycle. Some describe precision farming as applying the right inputs, at the right place, at the right time, right amount, and in the right manner.

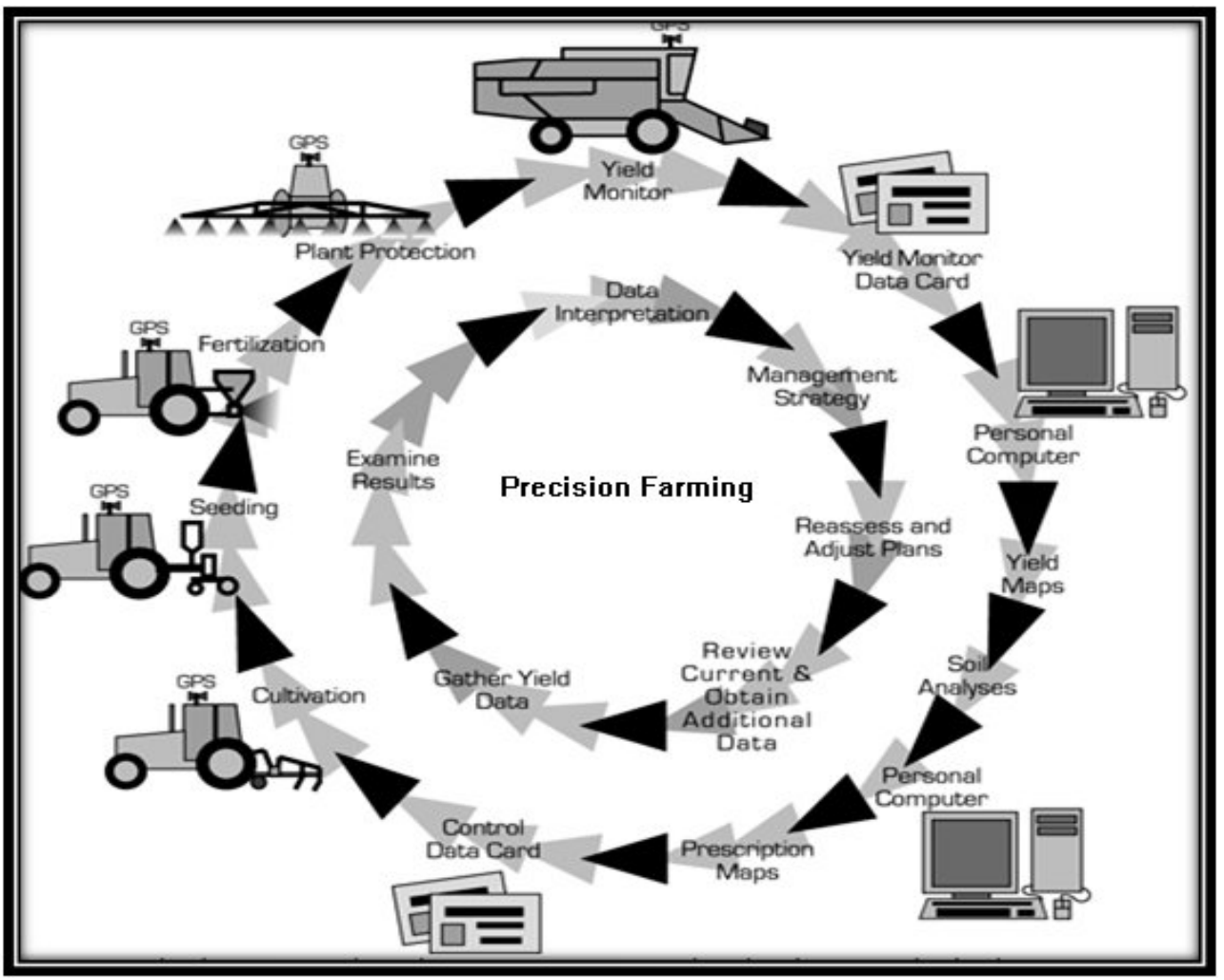

Fig. 9. Precision Farming Cycle (Grisso, 2009)

Implementation of management strategy based on precision farming concept is the vital factor to achieve a desired outcome for the farm. Managers should make out their own 
strategies that allow them to manage variability precisely. Blackmore (1999) stated the three types of variability that have been identified are spatial variability, which can be found through changes across the field, temporal variability which means changes over time and predictive variability, that identifies the difference between predicted and what actually happen in the field.

One of the precision farming approaches to manage spatial variability is site specific crop management (SSM). In order to match application of farm practices with soil and crop requirements, zone management was suggested. Zone management represents sub-fields with similar characteristics including soil properties, topography, slope, nutrient levels and so on.

\subsection{Paddy soil variability}

Soil variability in paddy fields is well recognized. The spatial description is an important component of the precision farming cycle for zone management practices. Precision farming requires topping up of only the nutrients that are lacking in the soil to attain the optimum yield with the least inputs. Manual soil sampling and the consequent laboratory analysis are expensive, labour intensive and requires a long time. The use of an on-the-go electrical conductivity (ECa) sensor can replace the traditional way of acquiring data in a more efficient way. Research results have confirmed the usefulness of the ECa data as a summary indicator for zoning paddy soils to facilitate water and fertilizer management.

Soil $\mathrm{EC}_{\mathrm{a}}$ measurements can provide information on soil texture, in addition to estimating soil water content. Maps of soil physical properties and yield maps have shown visible correlation. Soil $\mathrm{EC}_{\mathrm{a}}$ can serve as a proxy for soil physical properties such as organic matter (Jaynes, et al., 1994), clay content (Williams and Hoey, 1987), and cation exchange capacity (McBride, et al., 1990). These properties have a significant effect on water and nutrientholding capacity, which are major drivers of yield (Jaynes, 1995). The relationship between soil $\mathrm{EC}_{\mathrm{a}}$ and yield has been reported (Kitchen and Sudduth, 1996; Fleming, et al., 1998). Sudduth et al. (1998) found that within field variation in soil properties could be explained with soil conductivity measurements. They found a significant relationship between soil conductivity and topsoil depth and Fraisse et al. (1999) added to this work by using soil electrical conductivity for zone delineation. Both of these works concentrated on using soil $\mathrm{EC}_{\mathrm{a}}$ to characterize local spatial variability. Lund et al. (1998) show that sampling according to soil management zones identified with a soil conductivity map can be more effective than grid sampling.

\subsection{Materials and methods}

This study uses an on-the-go $\mathrm{EC}_{\mathrm{a}}$ sensor for producing $\mathrm{EC}_{\mathrm{a}}$ map and to use it for soil nutrients assessment. The field soil salinity readings can be obtained through this soil-toinstrument contact device that permits rapid soil $\mathrm{EC}_{\mathrm{a}}$ measurement without requiring a permanently buried detector. The study was conducted in paddy fields at Tanjung Karang, Selangor, Malaysia. The study site has 118 plots covering 144 ha with an average plot size of about 1.2 ha (Figs. 10 and 11). The EC sensor was pulled by a tractor at a speed of about 15 $\mathrm{km} \mathrm{h}^{-1}$ in a U-shape pattern $15 \mathrm{~m}$ apart. The data was later transferred to a notebook computer for generation of $\mathrm{EC}_{\mathrm{a}}$ maps using Surfer 7.0 software and ArcGIS 8.3 with Spatial 
and 3D Analyst extensions. A total of 63,578 data points were obtained. For comparison, a total of 236 soil samples were collected and analyzed in the laboratory for their chemical and physical properties.

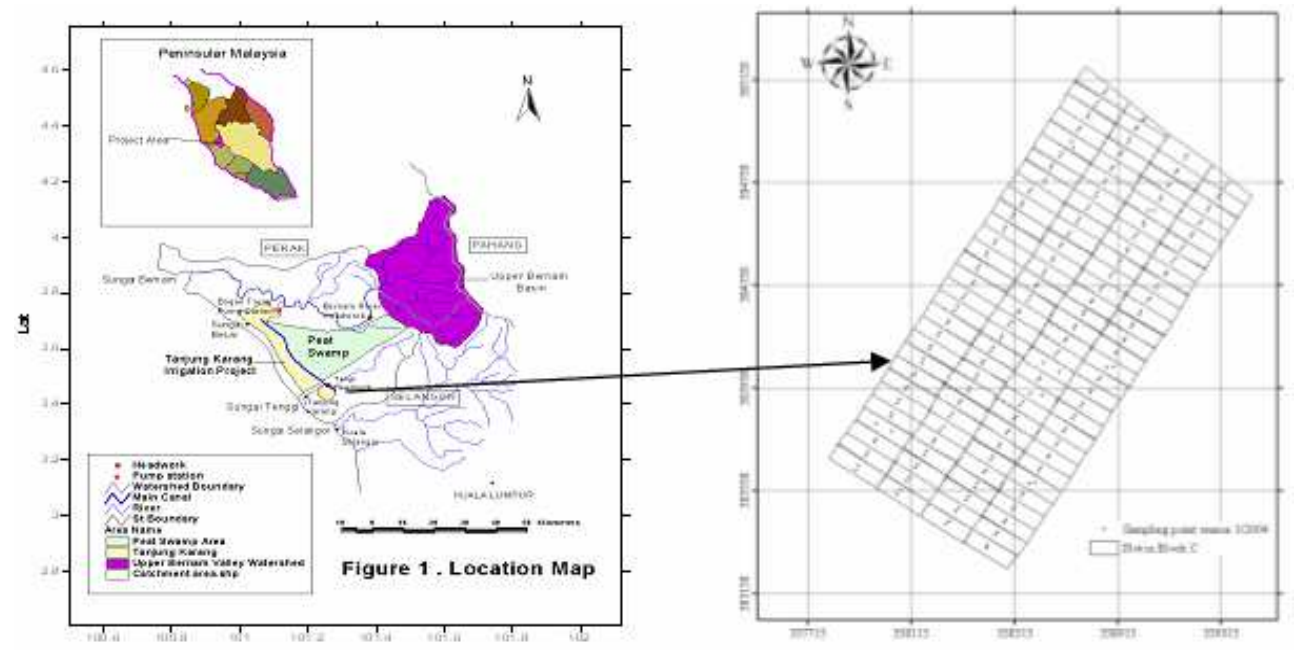

Fig. 10. Map of the Soil Chemical and Physical Sampling Points in Block C

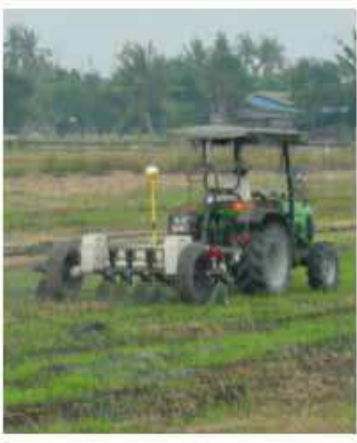

(a)

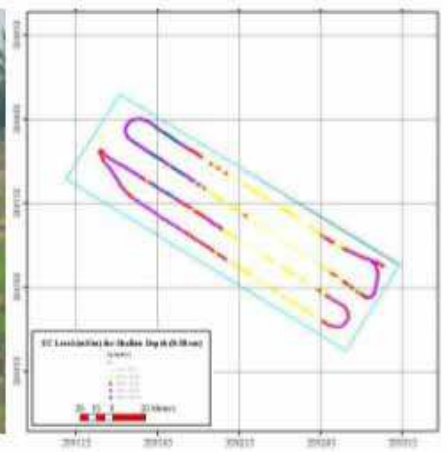

(b)

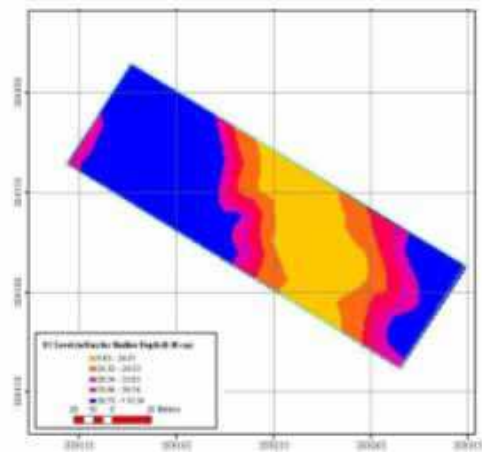

(c)

Fig. 11. (a) The EC sensor pulled by a tractor installed with DGPS in a paddy field, (b) results of 4 passes spaced $15 \mathrm{~m}$ apart in a typical 1.2 ha plot, and (c) krigged map of ECa.

\subsection{Results and discussion}

Soil $\mathrm{EC}_{\mathrm{a}}$ could provide a measure of the spatial differences associated with soil physical and chemical properties, which for paddy soil may be a measure of soil suitability for crop growth, its water demand and its productivity. The $\mathrm{EC}_{\mathrm{a}}$ maps indicated that it is similar to some soil nutrient maps. It was found that the technique could identify the zone of a former river located within the study area while detailed soil series map alone could not have found it. The relation of $\mathrm{EC}_{\mathrm{a}}$ to soil $\mathrm{P}, \mathrm{K}, \mathrm{Mg}$ and $\mathrm{CEC}$ in the paddy fields indicates that their 

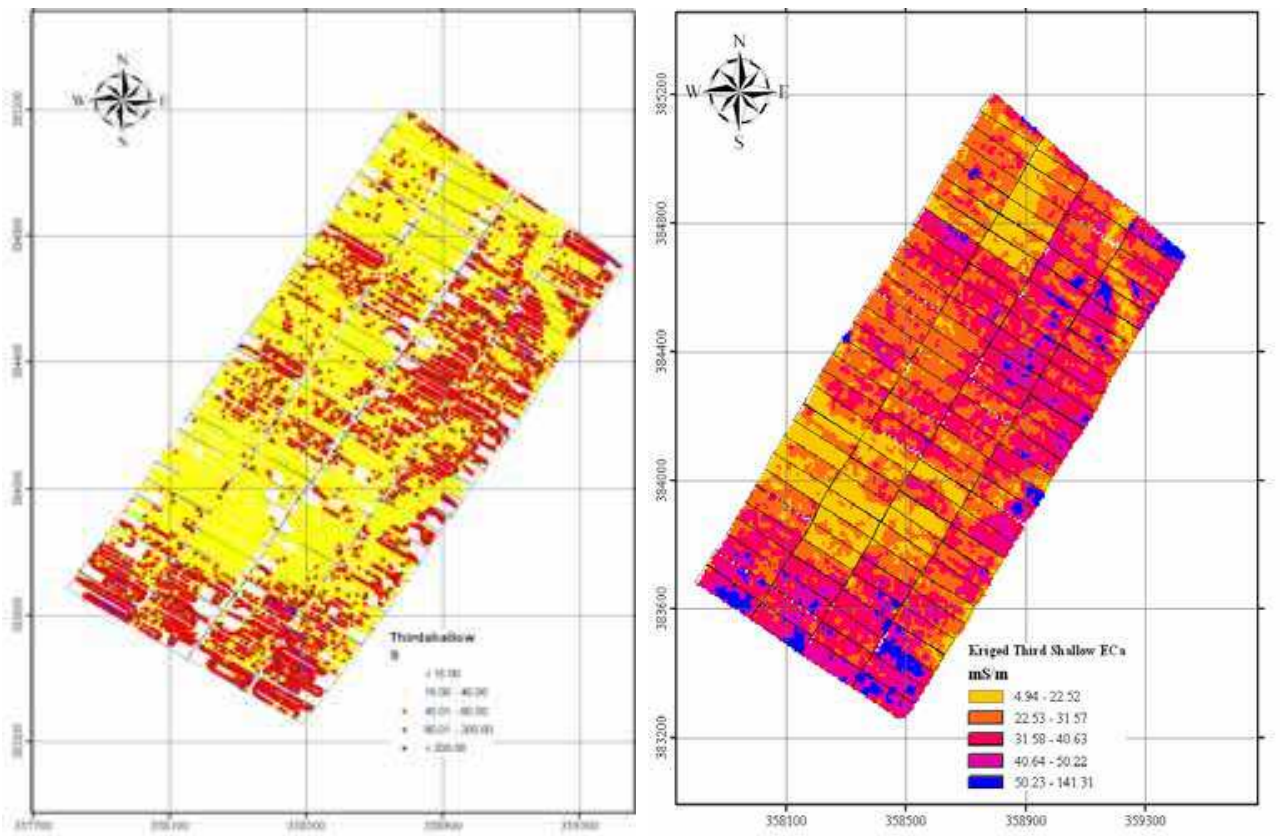

Fig. 12. Kriged Map for the Shallow $\mathrm{EC}_{\mathrm{a}}\left(\mathrm{mS} \mathrm{m}^{-1}\right)$ Classified by Smart Quantiles
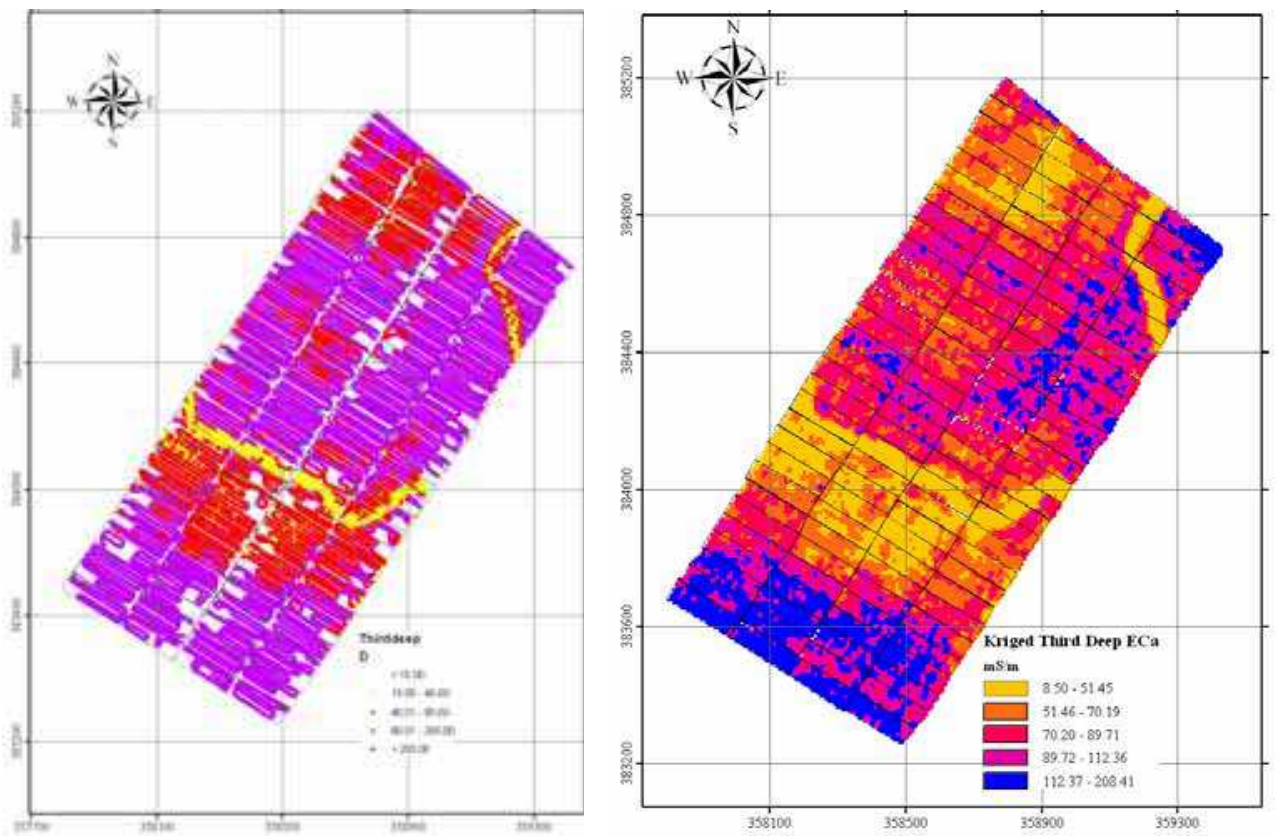

Fig. 13. Kriged Map for the Deep $\mathrm{EC}_{\mathrm{a}}\left(\mathrm{mS} \mathrm{m}^{-1}\right)$ classified by Smart Quantiles 
concentration can be estimated. Hence, quick nutrients determination can be done through the $\mathrm{EC}_{\mathrm{a}}$ sensor detection. The average values of $\mathrm{EC}_{\mathrm{a}}$ are significantly different between shallow $(0-30 \mathrm{~cm})$ and deep depths $(0-90 \mathrm{~cm})$ signifying differences in soil structure and nutrient status. The sensor can measure the soil $\mathrm{EC}_{\mathrm{a}}$ through the field quickly for detailed features of the paddy soil, and can be operated by just one worker.

The study area was divided into 5 manageable zones by smart quantiles method (ESRI, 2001). Fig. 12 shows the shallow $\mathrm{EC}_{\mathrm{a}}$ and Fig. 13 shows the deep $\mathrm{EC}_{\mathrm{a}}$. The map for the deep $\mathrm{EC}_{\mathrm{a}}$ shows the distribution clearly, especially for very low and low $\mathrm{EC}_{\mathrm{a}}$ levels. Fig. 13 shows the pattern of a former river clearly as a continuous line about $45 \mathrm{~m}$ wide at the northern and central regions of the study area.

The on-the-go EC sensor can be used to replace the traditional way of acquiring soil data by intensive sampling technique and laboratory analysis, which is usually time consuming and laborious. The resulting $\mathrm{EC}_{\mathrm{a}}$ maps are useful in showing the management zones for improving crop productivity with minimum inputs. The delineation by $\mathrm{EC}_{\mathrm{a}}$ showed that some soil properties significantly differ from zone to zone. A total of 21 parameters were significantly predicted by using $\mathrm{EC}_{\mathrm{a}}$ which shows that the $\mathrm{EC}$ probe can predict multivariables, hence reduces time for sampling and analyses.

\subsection{Matrix correlation of soil properties}

Pearson's 2-tailed test for soil chemical, physical and $\mathrm{EC}_{\mathrm{a}}$ correlation showed that shallow $\mathrm{EC}_{\mathrm{a}}$ has positively significant correlation to $\mathrm{pH}, \mathrm{EC}, \mathrm{CEC}, \mathrm{Mg}, \mathrm{Fe}$, clay and deep $\mathrm{EC}_{\mathrm{a}}$ and negatively significant correlation to $\mathrm{Al}$, fine sand and sand, at $99 \%$. It has positively significant correlation to $\mathrm{P}, \mathrm{K}$ and total cation, at $95 \%$. The highest $\mathrm{r}$ value was $0.70^{* *}$ for deep $\mathrm{EC}_{\mathrm{a}}$ and followed by $\mathrm{pH}\left(\mathrm{r}=0.39^{* *}\right)$. Deep $\mathrm{EC}_{\mathrm{a}}$ has positively significant correlation to $\mathrm{pH}, \mathrm{EC}, \mathrm{P}, \mathrm{CEC}, \mathrm{Mg}, \mathrm{K}, \mathrm{Na}, \mathrm{Fe}$, total cation, clay, fine sand, sand and shallow $\mathrm{EC}_{\mathrm{a}}$ and negatively significant correlation to $\mathrm{Al}$, at $99 \%$. The highest $\mathrm{r}$ value was 0.70 for shallow $\mathrm{EC}_{\mathrm{a}}$ and followed by $\mathrm{Mg}\left(\mathrm{r}=0.46^{* *}\right)$. Eltaib (2003) found that laboratory EC has highest correlation to $\mathrm{Mg}\left(\mathrm{r}=0.79^{* *}, \mathrm{n}=36\right)$ for this study area.

\subsection{Shallow $\mathrm{EC}_{\mathrm{a}}$ zoning characteristics}

The mean value for shallow $\mathrm{EC}_{\mathrm{a}}$ slightly increased from zone to zone and significantly isolated between zones. But, some mean values of soil properties (i.e. EC, OM, C, S, N, CEC, $\mathrm{Ca}, \mathrm{Na}$ and etc.) within the shallow $\mathrm{EC}_{\mathrm{a}}$ zones did not show linear trend as per mean shallow $\mathrm{EC}_{\mathrm{a}}$. The hypothesis for $\mathrm{EC}_{\mathrm{a}}$ zone establishment was that the soil properties within the zone were significantly different from zone to zone which indicated that soil $\mathrm{EC}_{\mathrm{a}}$ is a good zone delineator, a new classification approach for paddy soil properties.

The results indicate that the mean soil $\mathrm{pH}$ values within shallow $\mathrm{EC}_{\mathrm{a}}$ zone 1, 2 and 3 were not significantly different, but significantly higher than that in zone 4 and 5 . However, zone 1 has significantly high OM, C, total S, total N, ESP, fine sand and sand, and significantly low $\mathrm{Ca}$, total cation, BS and clay. Soil moisture, silt and coarse sand were not significantly different for all zones, at 0.05 . The shallow $\mathrm{EC}_{\mathrm{a}}$ proved that zone 1 (former river) contained higher $\mathrm{OM}$ as compared to other parts of the study area. Therefore, to manage that area based on shallow $\mathrm{EC}_{\mathrm{a}}$, it should be managed differently according to organic matter content. Mean shallow $\mathrm{EC}_{\mathrm{a}}$ for 5 zones has significantly negative correlation to soil $\mathrm{pH}(\mathrm{r}=-0.95)$ and 
total S $(r=-0.93)$ at $95 \%$ level. This indicates that soil $\mathrm{pH}$ and total S decreased when shallow $\mathrm{EC}_{\mathrm{a}}$ increased. Hence a good water management is to apply more irrigation water to increase the soil $\mathrm{pH}$ in zones 4 and 5.

\subsection{Deep $\mathrm{EC}_{\mathrm{a}}$ zoning characteristics}

The stratification of total N, BS and coarse sand by deep $\mathrm{EC}_{\mathrm{a}}$ were homogenous between the zones when their mean values within the zone were not significantly different at 0.05 . Mean soil OM, C and total S in zone 3 were significantly higher than those in other zones and they were different to shallow $\mathrm{EC}_{\mathrm{a}}$ zone where it indicated that zone 1 has significantly high $\mathrm{OM}$, $\mathrm{C}$ and total $\mathrm{S}$. Mean soil $\mathrm{pH}, \mathrm{EC}, \mathrm{P}, \mathrm{Mg}, \mathrm{K}, \mathrm{Fe}$, total cation and clay within zone 1 were significantly low as compared to other zones, but significantly high $\mathrm{Al}$, fine sand and sand. Deep $\mathrm{EC}_{\mathrm{a}}$ has significantly positive correlation to soil $\mathrm{pH}$ and $\mathrm{Fe}$ at 0.01 and significantly negative correlation to coarse sand at 0.05 .

\begin{tabular}{|c|c|c|c|c|c|c|}
\hline Soil Properties & Function & $\mathrm{R}^{2}$ & b0 & b1 & b2 & b3 \\
\hline \multicolumn{7}{|c|}{ Predictor: shallow $\mathbf{E C}_{\mathbf{a}}$} \\
\hline $\mathrm{pH}$ & Quadratic & $0.18^{* * *}$ & 4.8999 & -0.0042 & $1.0 \times 10^{-4}$ & \\
\hline EC & S & $0.07^{* * *}$ & -2.0959 & -5.7515 & & \\
\hline $\mathrm{N}$ & Compound & $0.02^{*}$ & 0.1301 & 0.9826 & & \\
\hline CEC & S & $0.06^{* * *}$ & 3.0187 & -5.1707 & & \\
\hline ESP & Exponential & $0.02^{*}$ & 2.7937 & -0.0053 & & \\
\hline \multicolumn{7}{|l|}{$\begin{array}{l}\text { Predictor: } \\
\text { deep } \mathrm{EC}_{\mathrm{a}}\end{array}$} \\
\hline $\mathrm{OM}$ & Inverse & $0.02^{*}$ & 8.2653 & 140.3670 & & \\
\hline C & Inverse & $0.02^{*}$ & 4.7938 & 81.4321 & & \\
\hline S & Inverse & $0.02^{*}$ & -0.0907 & 16.1845 & & \\
\hline $\mathrm{P}$ & Logarithm & $0.04^{* *}$ & 1.2987 & 2.0881 & & \\
\hline $\mathrm{Ca}$ & Inverse & $0.02^{*}$ & 4.5322 & -42.3070 & & \\
\hline $\mathrm{Mg}$ & Power & $0.28^{* * *}$ & 0.1362 & 0.6004 & & \\
\hline K & Quadratic & $0.05^{* *}$ & 0.1689 & 0.0028 & $-1.0 \times 10^{-5}$ & \\
\hline $\mathrm{Na}$ & Cubic & $0.07^{* *}$ & 0.0868 & 0.0093 & $-7.0 \times 10^{-5}$ & $1.5 \times 10^{-7}$ \\
\hline Total Cation & Quadratic & $0.13^{* * *}$ & 2.3696 & 0.0874 & $-4.0 \times 10^{-4}$ & \\
\hline $\mathrm{Al}$ & Cubic & $0.14^{* * *}$ & 1.0148 & 0.0903 & $-1.0 \times 10^{-3}$ & $2.8 \times 10^{-6}$ \\
\hline $\mathrm{Fe}$ & Exponential & $0.20^{* * *}$ & 0.2478 & 0.0054 & & \\
\hline BS & $S$ & $0.04^{* *}$ & 3.7573 & -11.1340 & & \\
\hline Moisture Content & Cubic & $0.04^{*}$ & 72.0409 & -0.6757 & $8.2 \times 10^{-3}$ & $-3.0 \times 10^{-5}$ \\
\hline Clay & Cubic & $0.18^{* * *}$ & 32.8506 & 0.0487 & $2.6 \times 10^{-3}$ & $-1.0 \times 10^{-5}$ \\
\hline Fine Sand & Quadratic & $0.14^{* * *}$ & 38.4191 & -0.3710 & $1.4 \times 10^{-3}$ & \\
\hline Sand & Cubic & $0.15^{* * *}$ & 30.6979 & -0.0402 & $-2.5 \times 10^{-3}$ & $1.3 \times 10^{-5}$ \\
\hline
\end{tabular}

Table 3. Significant Relationship of Soil Properties to $\mathrm{EC}_{\mathrm{a}}$ for the Study Area $(\mathrm{n}=236)$ 


\subsection{Model for soil properties estimations}

Results from the curve estimation for the independent variables of shallow and deep $\mathrm{EC}_{\mathrm{a}}$ indicate that $\mathrm{EC}_{\mathrm{a}}$ can be used to estimate multi-variables, 21 out of 24 variables. Shallow $\mathrm{EC}_{\mathrm{a}}$ has lesser soil properties compared to deep $\mathrm{EC}_{\mathrm{a}}$, where there were 16 and 21 variables, respectively. Most of the variables have high $\mathrm{R}^{2}$ values, except $\mathrm{pH}, \mathrm{EC}, \mathrm{N}, \mathrm{CEC}$ and ESP when the estimation is using deep $\mathrm{EC}_{\mathrm{a}}$ as independent variable. The relationship functions differed for some variables while others remained. The high $\mathrm{R}^{2}$ values for deep $\mathrm{EC}_{\mathrm{a}}$ indicate that variables were significantly estimated using deep $\mathrm{EC}_{\mathrm{a}}$ rather than shallow $\mathrm{EC}_{\mathrm{a}}$. The best model was judged based on their $\mathrm{R}^{2}$ where the estimation of soil $\mathrm{Mg}$ by deep $\mathrm{EC}_{\mathrm{a}}$ was the highest following by Fe, clay, $\mathrm{pH}$ and so on (Table 3).

\subsection{Yield variability and soil management zones}

A study was conducted to compare yield variability resulting from variability of soil ECa and other parameters for both the dry and wet seasons in the same 140 ha study area (Gholizadeh, 2011). Fig. 14 shows typical variability maps of the harvested yield compared to the variability in the bulk soil electrical conductivity, bulk soil density and soil texture. High yielding areas are associated with mid-range ECa, high clay and low sand, and low bulk density. Low yielding areas are associated with low ECa and high sand content. High yield is also associated with high $\mathrm{pH}$, high $\mathrm{EC}$ and high $\mathrm{OC}$, and vice versa. Hence water management that will allow increase in $\mathrm{pH}$ of the paddy soil is desirable.

\section{Water saving practices}

\subsection{Strategies for water saving}

Water saving practices, which require greater water control is associated with improving agronomic practices and the use efficiency of other inputs. Available strategies include developing improved varieties, improving agronomic management, changing the crop planting date, reducing water use for land preparation, changing rice planting practices with wet or dry seeding, reducing water use during crop growth through intermittent flooding, maintaining the soil in sub-saturated condition, alternate drying and wetting, optimum use of rainfall, supplementary irrigation of rain-fed low-land rice, water distribution strategies, water reuse or recycling and conjunctive use and alternative methods to flooding for growing irrigated rice under aerobic conditions.

High rice yield are obtained with good on-farm water management. Many researchers reported that continuous submergence with 5 to $7 \mathrm{~cm}$ of water is probably best for irrigated rice considering all factors. Submergence allows better weed control, higher efficiency of fertilizer use, and better insect and weed control with granular chemicals. Research has shown no difference in yield of rice grown at saturated soil condition with minimum water use but weed control is expected to be more costly.

Other researchers found optimum rice growth and production at $9 \mathrm{~cm}$ of ponded water depth. High values of water productivity were also found at this depth under different water regimes and fertigation levels. High water levels are required after transplanting for recovery and rooting stage and booting stage up to flowering stage. Low depths are required for tillering, panicle development and milk stage. Shallow depths promote 

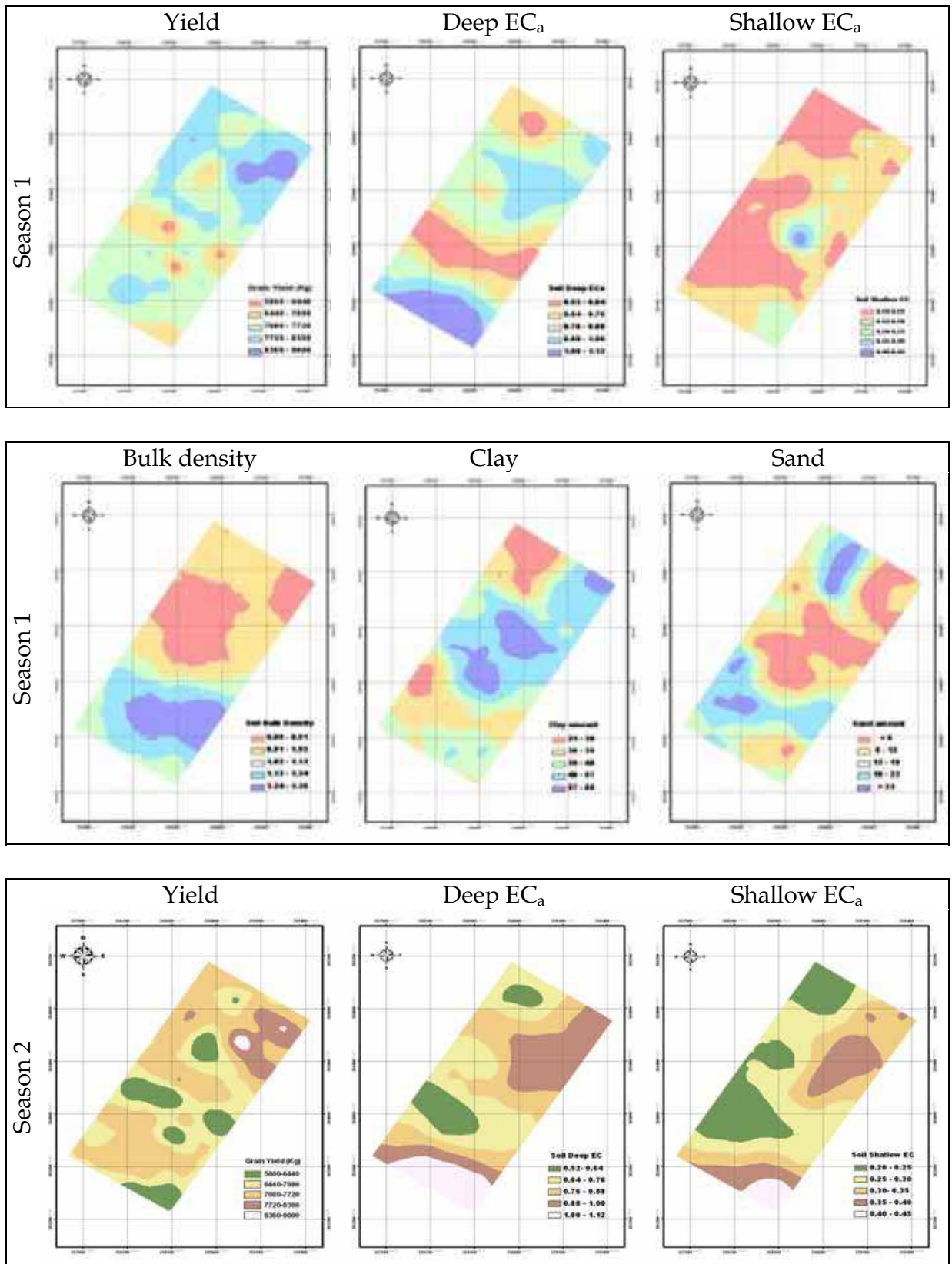

Fig. 14. (continues on next page)Variability in rice yield compared to ECa and soil physical properties in a 140 ha paddy fields for two seasons. Higher yielding areas are associated with mid-range ECad, medium ECas, low $\mathrm{Db}$, high clay and low sand. Low yielding areas are associated with low ECad, low ECas, high Db, medium clay, medium sand 


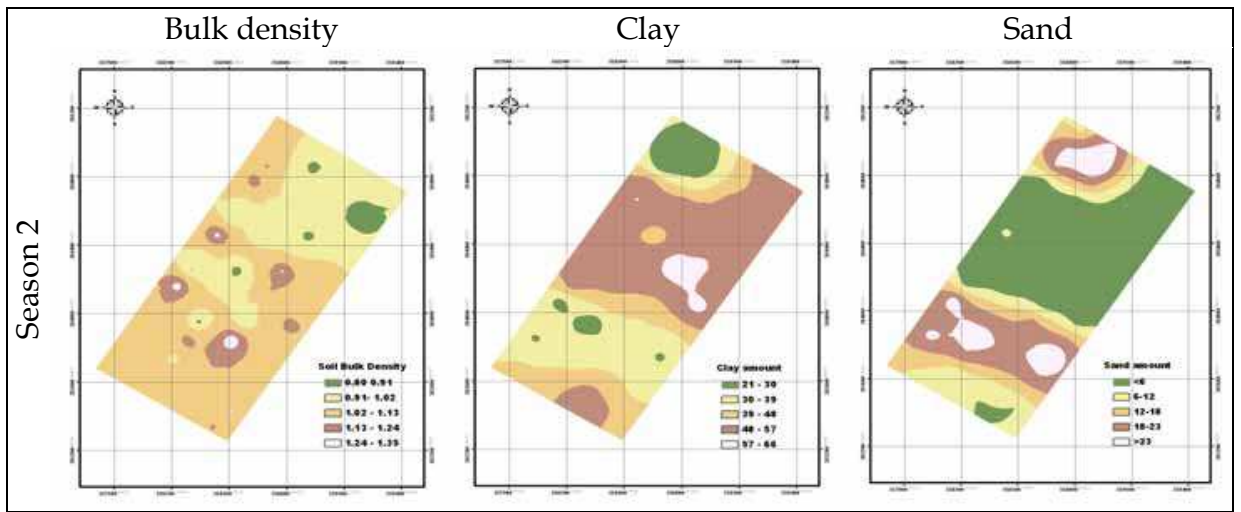

Fig. 14. (continued) Variability in rice yield compared to ECa and soil physical properties in a 140 ha paddy fields for two seasons. Higher yielding areas are associated with mid-range ECad, medium ECas, low Db, high clay and low sand. Low yielding areas are associated with low ECad, low ECas, high $\mathrm{Db}$, medium clay, medium sand

vigorous tillering. Mid-season drainage is important to cut-off the supply of ammonia- $\mathrm{N}$ to secure desirable plant characteristics, viz. short and erect upper 3 leaves, including flag leaf, and short lower inter-node to prevent lodging, to induce favourable ear (panicle) formation conditions, and to supply soils with oxygen to ensure healthy root growth.

Mid-season drainage removes hydrogen sulphide and other harmful substances, which are produced by microbial action under reductive conditions of submergence. Water $(5 \mathrm{~cm})$ is needed at milk stage for translocation of nutrients stored in plant body to ear or panicle for healthy development of developing grain or spikelet.

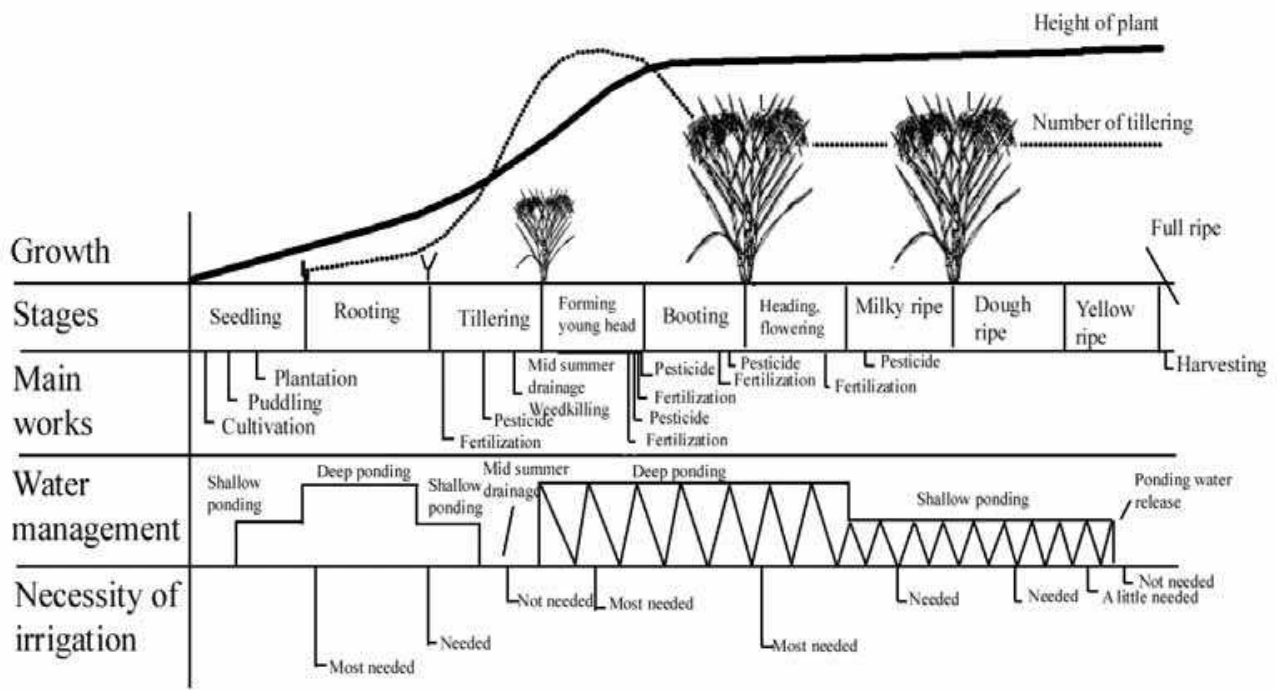

Fig. 15. Rice growth, agricultural works and water management (Maruyama and Tanji, 1997) 


\subsection{Rice growing calendar and water management}

Maruyama and Tanji (1997) showed that the growth stages of rice can be divided into ten growth stages associated with water management practices in Japan as shown in Fig. 15. The paddy farmers must control the field water depth precisely according to the growth stage in order to reap the benefit of higher water productivity.

\subsection{Water-efficient irrigation regimes to increase water productivity}

Mao Zhi (2000) stated that rice is one of the most important food crops contributing over $39 \%$ of the total food grain production in China. Out of 113 million hectares of area sown under food crops $28 \%$ is covered by rice. The traditional irrigation regime for rice, termed as "continuous deep flooding irrigation" was applied in China before 1970s. Since 1980s, the industry water supply, urban and rural domestic water consumption has been increasing continuously. The shortage of water resources became an important problem and many water efficient irrigation regimes for rice have been tested, advanced, applied and spread in different regions of China.

Based on the results of experiment and the experience of spread of these new irrigation regimes, the following conclusions were drawn by the author:

- Three essential water efficient irrigation regimes (WEI) for rice as shown in Fig. 16, which include the regimes of combining shallow water depth with wetting and drying (SWD), alternate wetting and drying (AWD) and semi-dry cultivation (SDC), have been adopted in the different rice growing regions of China.

- In comparison to the traditional irrigation regime (TRI), rice yield can be increased slightly, water consumption and irrigation water use of paddy field can be decreased greatly and the water productivity of paddy field can be increased remarkably under the WEI.

- The main causes of decrease of water consumption and irrigation water use are the decrease of the percolation rate in paddy field and increase in the utilization of rainfall.

- A positive environmental impact is obtained by adopting WEI, the main cause of getting bumper yields were that the ecological environment under WEI is more favourable for the growth and development of rice than that under TRI.

- For avoiding the decrease of yield under WEI, some measures, as timely irrigation, coordinating irrigation with fertilization and weed control must be used since shortage of water resources in China is becoming more serious each year, the water efficient irrigation techniques should be further investigated and adopted on large areas.

\subsection{Distribution variability of effective rainfall}

With global warming and climate change, greater competition is expected among water users, and paddy irrigation may be sacrificed during water shortage in dry months favouring domestic and industrial users. However, rice granaries practicing multiple cropping have yet to improve on the use of "effective rainfall". Currently, the measurement of rain falling in a rice growing area is based solely on the available rain gauge network. These gauges are located at convenient locations which may not be representative of the whole rice growing 
area. Hence, under- or over-estimation of rainfall distribution and runoff occurs and consequently affects the management of floods during rainy seasons or base flow for irrigation during dry seasons. Therefore, better estimates of mean areal rainfall are needed as contribution of effective rainfall in the water balance during the irrigation season.

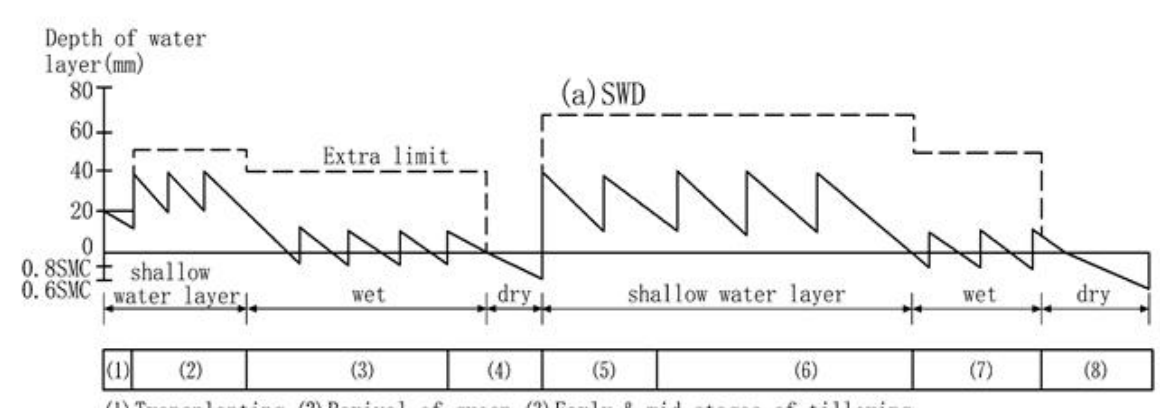

(1) Transplanting, (2) Rerival of green, (3) Early \& mid stages of tillering,

(4) Late stage of tillering, (5) Elongating \& booting, (6) Heading \& Flowering,

(7) Milk ripening, (8) Yellow repening

(b) AWD (For early rice)
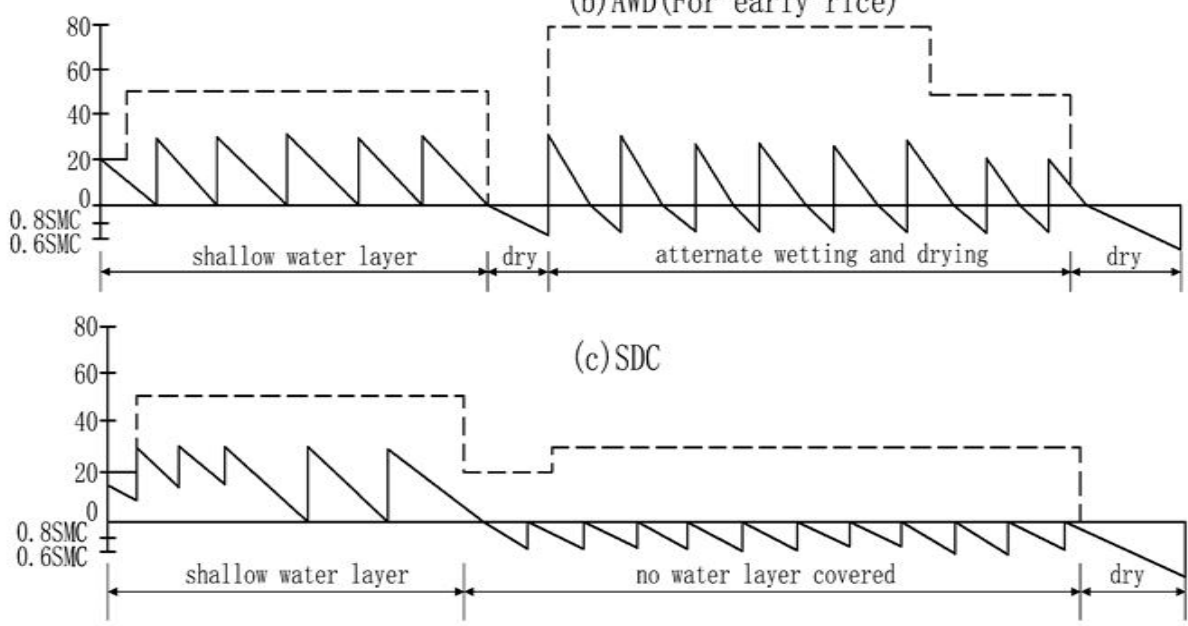

Fig. 16. Description of Different Water Efficient Regimes (Mao Zhi, 2000)

A new technique to improve rainfall distribution estimation based on weather radar-derived rainfall throughout the rice growing area was developed by UPM using GIS tools. Virtual rainfall stations are created uniformly throughout the area to improve the spatial distribution of rainfall over a rice granary or a watershed with low density rain gauge network. Virtual rainfall stations can be distributed in terms of grid centres to cover the whole study area as shown in Fig. 17. The rainfall data for these virtual rain gauges are estimated from raw radar data available from the Malaysian Meteorological Department using a newly developed Program called UPM ViRaS RaDeR ver1.0 (Amin et al., 2010). The derived rainfall data is 


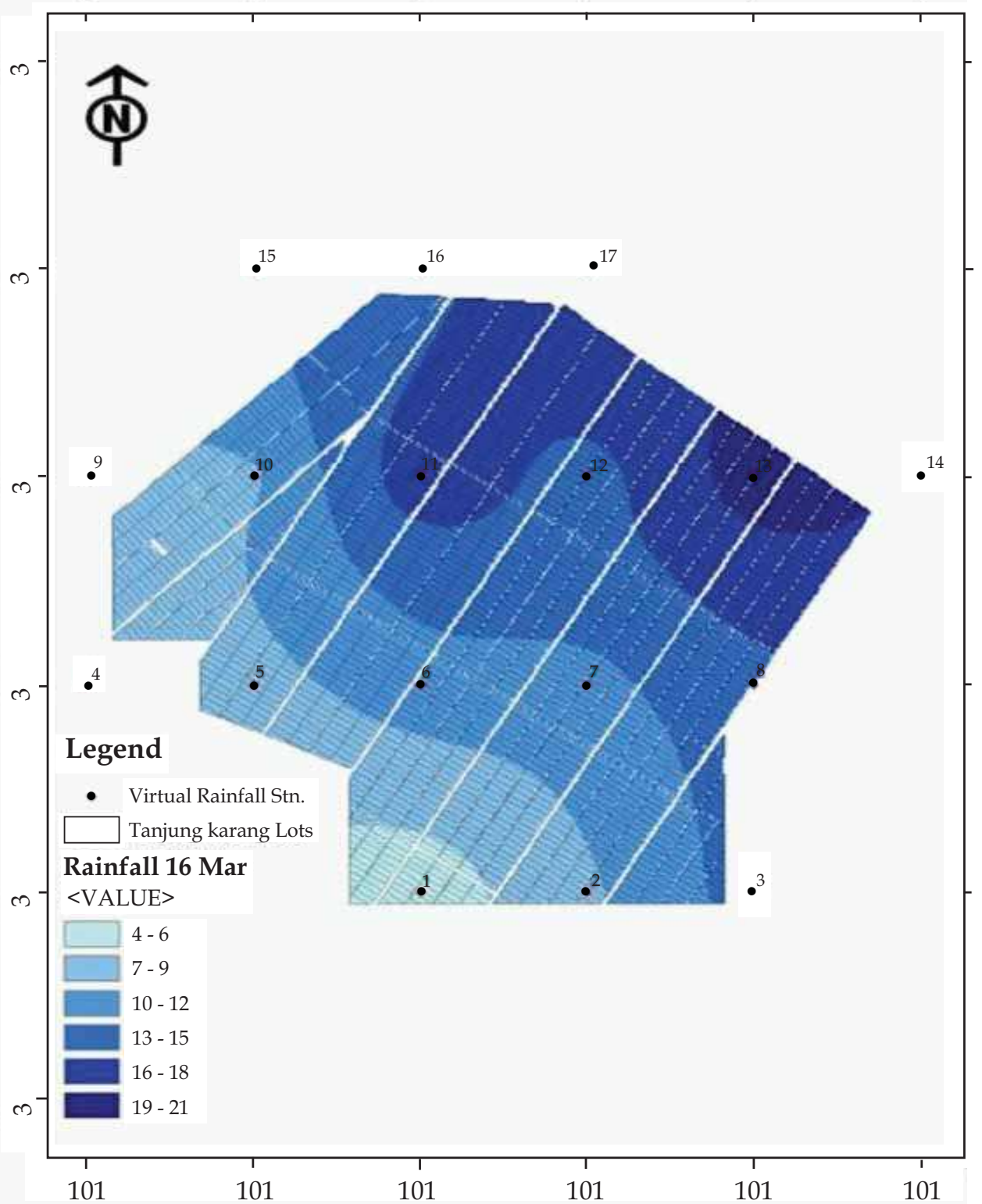

Fig. 17. (continues on next page) The radar derived rainfall data from 17 Virtual Rainfall Stations in a 2300 ha Sawah Sempadan Irrigation Compartment produced rainfall distribution pattern which otherwise would always be uniformly distributed since there is only one rain-gauge for the whole area 


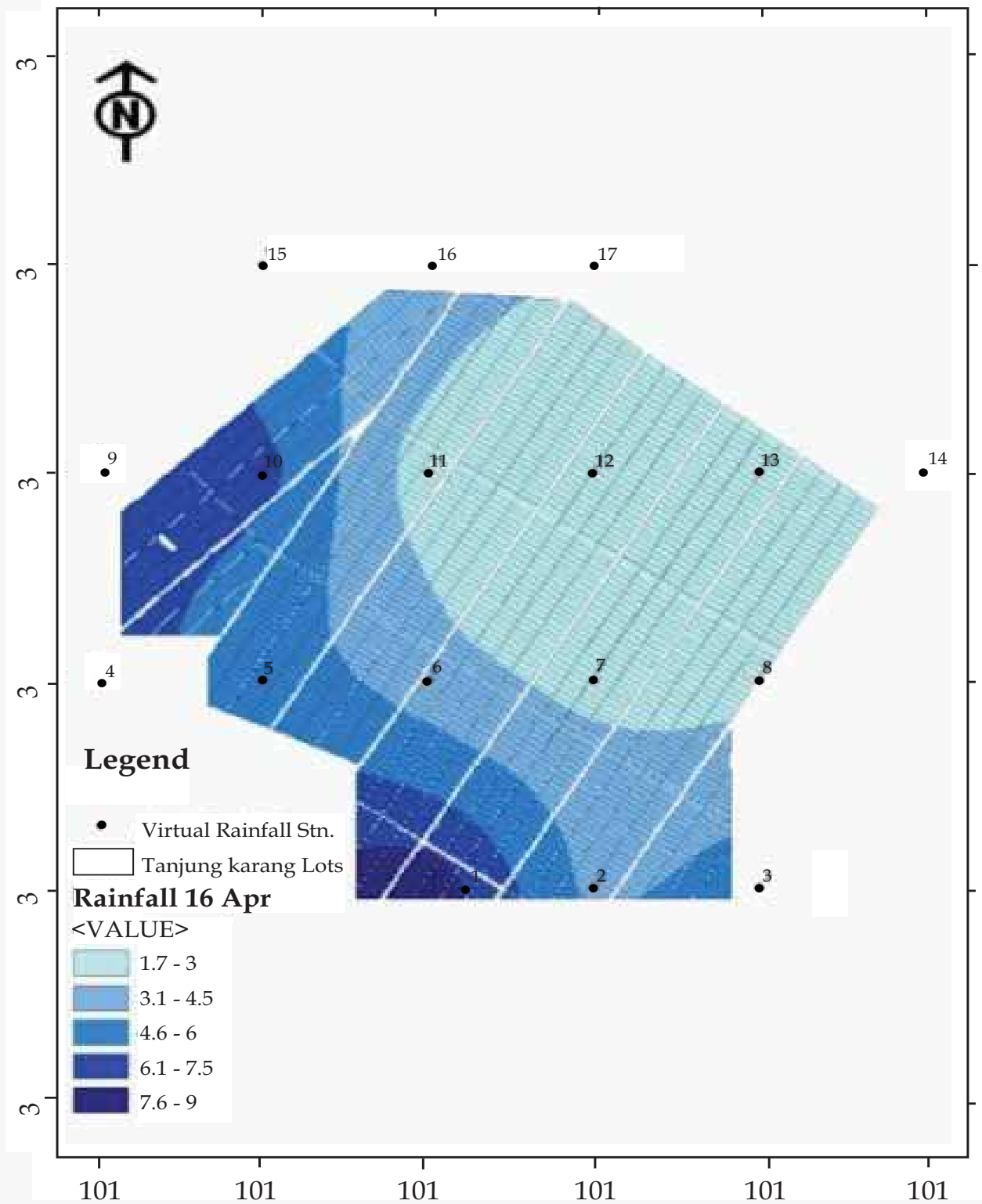

Fig. 17. (continued) The radar derived rainfall data from 17 Virtual Rainfall Stations in a 2300 ha Sawah Sempadan Irrigation Compartment produced rainfall distribution pattern which otherwise would always be uniformly distributed since there is only one rain-gauge for the whole area 
then compared and calibrated with actual gauge rainfall records for the same periods to identify the calibration factor. RaDeR provides rainfall distribution pattern which otherwise would always be uniformly distributed since there is only one rain-gauge for the whole area. The calibrated radar derived rainfall data will next be used as improved rainfall input in the hydrological model for watershed runoff estimation. On the other hand, knowing the amount of rainfall that occurred in a rice granary or a farm, a suitable amount of irrigation water can be supplied precisely and better irrigation water management can be adopted. Irrigation can be stopped when enough rain water has already refilled the soil moisture reservoir or standing water depth in the paddy fields. Hence the effective rainfall will save some amount of irrigation water supply and used for other purposes.

\section{Summary}

In anticipation of future greater competition for irrigation water due to climate change and global warming, paddy water management should be more focused towards water saving and precision irrigation. This book chapter has described new indicators for evaluating the performance of different aspects of an irrigation system for rice cultivation. A GIS-based interactive assessment tool is given using a new concept to characterize the irrigation delivery performance as the season advances. The weakness of a widely used Relative Water Supply (RWS) concept is overcome by using the new indicators, viz. Rice Relative Water Supply (RRWS), Cumulative Rice Relative Water Supply (CRRWS) and Ponding Water Index (PWI). The RRWS can distinctly characterize the oversupply condition for RRWS $>1.0$ and undersupply condition for RRWS $<1.0$ on irrigation delivery for any given period. A value of 1.0 for RRWS indicates an irrigation delivery that perfectly matches the actual field water demand. A user-interface was developed for structuring the assessment tool within ArcGIS platform. The system can instantly give information on the uniformity of water distribution and the shortfall or excess and what decisions to adopt for the next period. The results are displayed on the computer screen together with colour-coded maps, graphs and tables in a comprehensible form. The system can be adopted as an analytical and operational tool for the irrigation managers to evaluate various water allocation scenarios and water management options.

Water savings can be obtained by practicing precision farming of rice in lowland paddy fields. However a rapid assessment of the paddy soil variability needs to be determined, for example through mapping of the bulk electrical conductivity (ECa) of the paddy fields, so that variable treatments of the management zones can be adopted to save the precious resources. ET monitoring is necessary to determine the required amount of water at each crop growth stage, and the rainfall distribution pattern in the irrigation scheme should be considered to make better use of effective rainfall with respect to the stage of crop development. The practice of precision farming (i.e. applying the right input, at the right place, at the right time, at the right amount and in the right manner using the right tools) will ensure high water and land productivity for a sustainable rice production to feed the growing world population.

\section{Acknowledgements}

The financial support for the research provided by the Government of Malaysia through MOSTI is gratefully acknowledged. Cooperation from all members of the Precision Farming 
Engineering Research and Development (PREFERD) Group UPM, staff at the Tanjung Karang Irrigation Scheme and Integrated Agricultural Development Area (IADA), Kuala Selangor, Malaysia and the SMART Farming Technology Centre of Excellence UPM is highly appreciated.

\section{References}

[1] Plusquellec H., Burt C. and Wolter H.W. Modern water control in irrigation. World Bank Technical Paper no. 246 - Irrigation and Drainage series, Washington D.C. (1994).

[2] De Datta S.K. Principles and practices of rice production. Los Baños, Philippines: International Rice Research Institute, 1981, 618 p.

[3] Anbumozhi V., Yamaji T. and Tabuchi T. Rice crop growth and yield as influenced by changes in standing water depth, water regime and fertigation level. J. Agril. Water Mgmt., 1998, 37: 241-253.

[4] Abernethy C.L. and Pearce G.R. Research needs in third world irrigation, Hydraulics Research Limited, Wallingford, England, 1987.

[5] Rao P.S. Review of selected literature on indicators of irrigation performance. IIMI Research Paper, 1993.

[6] Levin G. Relative water supply: An explanatory variable for irrigation systems, Technical report no. 6, Cornell University, New York, 1982.

[7] Nihal F. Monitoring irrigation water delivery performance: The concept of Cumulative Relative Water Supply (CRWS). In: Proceedings of an International Conference on Advances in Planning, Design, and Management of Irrigation Systems as related to Sustainable Land Use, Katholic Universiteit Leuven, Belgium, 1992, pp 525-534.

[8] Shakthivadivel R., Douglas J.M., Nihal F. Cumulative relative water supply: A methodology for assessing irrigation system performance. Irrigation and Drainage Systems 7, 1993 pp. 43-67.

[9] Oad R. and Podmore T.H. Irrigation management in rice-based agriculture: Concept of relative water supply. ICID Bulletin 38(1), 1988, pp. 1-12.

[10] Weller J.A. An evaluation of the Porac irrigation system. Irrigation and Drainage Systems 5(1), 1991, pp. 1-17.

[11] Rowshon M.K., Kwok C.Y., Lee T.S. GIS-Based Scheduling and Monitoring of Irrigation Delivery for Rice Irrigation System-Part II: Monitoring. Agricultural Water Management, vol 117, 2003, pp. 117-126.

[12] Knox J.W. and Weatherhead E.K. The application of GIS to irrigation water resources management in England and Wales. Geographical Journal 165(1), 1999, 90-98.

[13] Tsihrintzis V.A., Hamid R. and Fuentes H.R. Use of geographic information systems (GIS) in water resources: a review. Water Resour. Manage, 10, 1996, 251-257.

[14] DID and JICA. The study on Modernization of Irrigation Water Management System in the Granary Area of Peninsular Malaysia, Draft Final Report, Volume -II, Annexes, March 1998. 
[15] Hassan SMH. Estimation of rice evapotranspiration in paddy fields using remote sensing and field measurements. Unpublished PhD Dissertation, University Putra Malaysia, (2005), pp 212.

[16] Molden, D., Sakthivadivel, R., Perry, C. J., de Fraiture, C., and Kloezen, W.H. Comparing the performance of irrigated agricultural systems, IIMI News, Vol. 1, No. 3, Colombo, Sri Lanka, 1997.

[17] Grisso, R. 2009. Precision Farming: A Comprehensive Approach. Extension publication 442-500, Biological Systems Engineering, Virginia Tech. USA

[18] Eltaib, S.M.G., 2003. Spatial variability of soil electrical conductivity, nutrients and rice yield, and site-specific fertilizer management. PhD Thesis UPM.

[19] ESRI. 2001. Using ArcGIS, Geostatistical Analyst. ESRI, CA.

[20] Fleming, K.L., D.W. Weins, L.E. Rothe, J.E. Cipra, D.G. Westfall and D.F. Heerman. 1998. Evaluating Farmer Developed Management Zone Maps for Precision Farming. The $4^{\text {th }}$ Int'l. Conf. On Prec. Agric. St. Paul, MN, p. 138.

[21] Fraisse, C. W., Sudduth, K. A. and Kitchen, N. R. 1999. Evaluation of Crop Models to Simulate Site-Specific Crop Development and Yield. In: Proc of the 4th Int Conf. on Precision Agriculture, P. C. Robert et al. (Eds.) p. 1297-1308.

[22] Jaynes, D.B., Novak, J.M., Moorman, T.B. and Cambardella, C.A., 1994. Estimating Herbicide Partition Coefficients from Electromagnetic Induction Measurements. J. Envt. Quality, 24: 36-41.

[23] Jaynes, D.B., T.S. Colvin, and J. Ambuel, 1995. Yield mapping by electromagnetic induction. p. 383-394. In P.C. Robert et al. (ed.) Proc. of site-specific management for agricultural systems, 2nd, Minneapolis, MN.

[24] Kitchen, N.R, and K.A. Sudduth, 1996. Predicting Crop Production using Electromagnetic Induction. Information Agriculture Conference Proceedings, Urbana IL.

[25] Lund, E.D., Christy, C.D., Drummond, P.E. 1998. Applying Soil Electrical Conductivity Technology to Precision Agriculture. Proceedings of the 4th Int Conference on Precision Agriculture, St. Paul MN.

[26] McBride, R.A.,A.M.Gordon, and S.C. Shrive. 1990. Estimating Forest Soil Quality from Terrain Measurements of Apparent Electrical Conductivity. Soil Sci. Soc. Am. J. 54:290-293.

[27] Sudduth K.A., C.W. Fraisse, S.T. Drummond and N.R. Kitchen. 1998. Integrating Spatial Data Collection, Modelling and Analysis for Precision Agriculture. Presented at the First International Conference on Geospatial Information in Agriculture and Forestry, Lake Buena Vista, Florida. http://www.fse.missouri.edu/ars/projsum/erim_3.pdf.

[28] Williams, B.G., and D. Hoey. 1987. The Use of Electromagnetic Induction to Detect the Spatial Variability of the Salt and Clay Contents of Soils. Aust. J. Soil Res. 25:2127.

[29] Maruyama, T and K.K. Tanji, 1997. Physical and Chemical processes of soil related to paddy drainage, 99-101.

[30] Mao Zhi, 2000. Water-efficient irrigation regimes of rice for sustainable increases in water productivity. In Proceedings of International Rice Research Conference, International Rice Research Institute, Laguna, Philippines. 
[31] Asa Gholizadeh, 2011. Apparent Electrical Conductivity and Vis-NIR reflectance for Predicting Paddy Soil Properties and Rice Yield. Unpublished PhD Thesis, UPM Serdang Selangor Malaysia.

[32] Amin, MSM, ARM Waleed, and MY Abdullah, 2010. Improving Water Management using Virtual Rainfall Stations with Radar Derived Rainfall Data. In Proc. of Intnl. Workshop on Integrated Lowland Development and Management, Palembang City, Indonesia, 18-20 March 2010. 


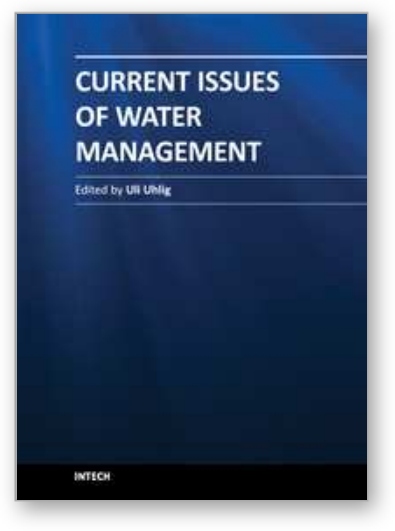

\author{
Current Issues of Water Management \\ Edited by Dr. Uli Unlig
}

ISBN 978-953-307-413-9

Hard cover, 340 pages

Publisher InTech

Published online 02, December, 2011

Published in print edition December, 2011

There is an estimated 1.4 billion $\mathrm{km} 3$ of water in the world but only approximately three percent (39 million $\mathrm{km} 3$ ) of it is available as fresh water. Moreover, most of this fresh water is found as ice in the arctic regions, deep groundwater or atmospheric water. Since water is the source of life and essential for all life on the planet, the use of this resource is a highly important issue. "Water management" is the general term used to describe all the activities that manage the optimum use of the world's water resources. However, only a few percent of the fresh water available can be subjected to water management. It is still an enormous amount, but what's unique about water is that unlike other resources, it is irreplaceable. This book provides a general overview of various topics within water management from all over the world. The topics range from politics, current models for water resource management of rivers and reservoirs to issues related to agriculture. Water quality problems, the development of water demand and water pricing are also addressed. The collection of contributions from outstanding scientists and experts provides detailed information about different topics and gives a general overview of the current issues in water management. The book covers a wide range of current issues, reflecting on current problems and demonstrating the complexity of water management.

\title{
How to reference
}

In order to correctly reference this scholarly work, feel free to copy and paste the following:

M.S.M. Amin, M.K. Rowshon and W. Aimrun (2011). Paddy Water Management for Precision Farming of Rice, Current Issues of Water Management, Dr. Uli Uhlig (Ed.), ISBN: 978-953-307-413-9, InTech, Available from: http://www.intechopen.com/books/current-issues-of-water-management/paddy-water-management-forprecision-farming-of-rice

\section{INTECH}

open science | open minds

\section{InTech Europe}

University Campus STeP Ri

Slavka Krautzeka 83/A

51000 Rijeka, Croatia

Phone: +385 (51) 770447

Fax: +385 (51) 686166

www.intechopen.com

\section{InTech China}

Unit 405, Office Block, Hotel Equatorial Shanghai

No.65, Yan An Road (West), Shanghai, 200040, China

中国上海市延安西路65号上海国际贵都大饭店办公楼 405 单元

Phone: +86-21-62489820

Fax: +86-21-62489821 